\title{
Novel antibiotic mode of action by repression of promoter isomerisation
}

Leena Kerr ${ }^{1,3}$, Douglas F. Browning ${ }^{4}$, Kimon Lemonidis ${ }^{5}$, Talal Salih ${ }^{1,6}$, lain S.

Hunter ${ }^{1}$, Colin J. Suckling ${ }^{2}$, Nicholas P. Tucker ${ }^{1 *}$

${ }^{1}$ Strathclyde Institute of Pharmacy and Biomedical Sciences, University of

Strathclyde, 161 Cathedral Street, Glasgow, G4 ORE, UK

${ }^{2}$ Department of Pure and Applied Chemistry, University of Strathclyde, 295

Cathedral Street, Glasgow, G1 1XL, UK

${ }^{3}$ School of Energy, Geoscience, Infrastructure and Society, Institute of Life and Earth

Sciences, Heriot-Watt University, Riccarton, Edinburgh, EH14 4AS, UK

${ }^{4}$ Institute of Microbiology and Infection, School of Biosciences, University of

Birmingham, Birmingham, B15 2TT, UK

${ }^{5}$ Institute of Molecular Cell and Systems Biology, University of Glasgow, Glasgow,

G12 8QQ, UK

${ }^{6}$ College of Science, University of Mosul, Mosul, Iraq

Contact; nick.tucker@strath.ac.uk 


\section{Abstract:}

Rising levels of antibiotic resistance dictate that new antibiotics with novel modes of action must be found. Here, we investigated the mode of action of a novel antibiotic that is a member of a family of synthetic DNA minor groove binding (MGB) molecules. MGB-BP-3 has successfully completed a Phase II clinical trial in humans as an orally administered drug for the treatment of chronic Clostridioides (Clostridium) difficile infections, where it outperformed the existing benchmark (vancomycin). MGB-BP-3 is active against a variety of Gram-positive pathogens including Staphylococcus aureus, which was used as the model for this study. The transcriptomic response of $S$. aureus to MGB-BP-3 identified downregulated promoters. DNase I and permanganate footprinting demonstrated binding to essential SigA promoters and the inhibition of promoter isomerisation by RNA polymerase holoenzyme. Promoters controlling DNA replication and peptidoglycan biosynthesis are amongst those affected by MGB-BP-3. Thus, MGB-BP-3 binds to and inhibits multiple essential promoters on the $S$. aureus chromosome, suggesting that evolution of resistance by drug target mutation should be unlikely. In confirmation, laboratory-directed evolution against sub-inhibitory concentrations of MGB-BP-3 resulted in no resistance whereas resistance to the single target RNA-polymerase inhibitor rifampicin arose rapidly.

\section{Introduction:}

DNA minor-groove binding (MGB) drugs have a variety of effects on infectious agents including bacteria, fungi, parasites and viruses [1]. Distamycin, a natural product made by Streptomyces, has been used as a chemical biology probe to examine the structure of AT-rich promoter UP elements in Escherichia coli and has shown promise as an anti-cancer agent [2, 3]. Distamycin inhibits the binding of the transcriptional 
machinery to DNA $[4,5]$, but its toxicity to humans has prevented it from being developed as an anti-infective agent. Using distamycin as a design concept, a family of synthetic MGBs was synthesised [e.g. 6]. These structural variants retained DNAbinding and anti-Gram-positive activity but lacked human toxicity [6]. One of these, MGB-BP-3 (Figure 1a), has been taken forward for clinical development. It has strong $(<1 \mu \mathrm{g} / \mathrm{ml})$ antibacterial activity against methicillin-resistant and -susceptible Staphylococcus species, pathogenic Streptococcus species, vancomycin-resistant and susceptible Enterococcus, and Clostridioides (Clostridium) difficile. Its oral formulation, developed for the treatment of $C$. difficile infections, has successfully completed a Phase II clinical trial. Subsequently, different compounds have been found to be active against a wide variety of pathogens and some cancer cell lines [711]. Antibacterial activity of MGB-BP-3 is confined to Gram-positive bacteria and dose response curves show a steep decrease in viability over a narrow concentration range, suggesting a catastrophic failure in the bacterium rather than an interaction with a single receptor typified by a sigmoidal dose-response curve. Members of this MGB family have typically been shown to bind to $6-8$ base pairs in dsDNA $[6,12]$. Whilst it can be reasonably anticipated that the main mode of action of MGB-BP-3 is by binding to DNA, the detailed biological consequences of binding to DNA that eventually lead to cell death cannot be predicted and need further investigation. Moreover, a short minor groove binder such as MGB-BP-3 could bind to many sites on the bacterial genome with the potential to interfere with a number of essential biological processes. Here, we have used RNA-Sequencing to probe the transcriptional consequences of MGB-BP-3 binding to the $S$. aureus chromosome. This approach, along with qPCR melt analysis, phenotypic microarrays, DNase I footprinting and potassium 
permanganate footprinting allows the identification of promoters that are sensitive to MGB-BP-3 shedding new light on its mode of action against $S$. aureus.

These data indicate multiple chromosomal binding sites, suggesting that generation of resistance to this type of drug would be significantly less than for drugs with a single target. In order to test this hypothesis we used a directed evolution approach to compare the evolvability of resistance to MGB-BP-3 and rifampicin.

Together, these results provide a comprehensive profile of the effect of MGB-BP-3 on S. aureus in culture and support the concept of multiple antibacterial actions via selective, but simultaneous, inhibition of a subset of promoters.

\section{Materials and Methods:}

\section{Bacterial strain and growth conditions:}

S. aureus subsp. aureus strain NCTC8325 from the HPA Culture Collection was used throughout this study with the exception of the resistance/evolution experiment for which S. aureus ATCC 43300 (resistant to methicillin and oxacillin) was used. Bacteria were grown for transcriptomic analyses according to the following: pre-cultures were prepared by inoculation from a frozen bead stock (Microbank, Fisher Scientific UK) to $5 \mathrm{ml}$ of Tryptic Soya Broth (Sigma-Aldrich) and incubated overnight. Six $250 \mathrm{ml}$ shake flasks with $50 \mathrm{ml}$ of cation-adjusted Mueller-Hinton broth 2 (Sigma-Aldrich) were inoculated to $\mathrm{OD}_{600}$ of 0.05 using a pre-culture. All cultures were incubated at $250 \mathrm{rpm}$ and $37^{\circ} \mathrm{C}$. At $\mathrm{OD}_{600}$ of $0.3,0.5 \times$ MIC of MGB-BP-3 dissolved in DMSO was added to the cultures in triplicate (treated samples), whereas control samples (also in triplicate) where treated with same volume of DMSO only (untreated samples). Samples of 10 $\mathrm{ml}$ were withdrawn 10 min after addition of antibiotic. The samples were immediately 
transferred to RNAprotect Bacteria Reagent (Qiagen) following the supplier's instructions. The MIC was determined using the broth dilution method on 96-well plate in cation-adjusted Mueller-Hinton broth 2 (Sigma-Aldrich).

\section{Microscopy:}

S. aureus NCTC8325 cells, grown to 0.3-0.4 OD600 in nutrient broth (Oxoid), were treated with MGB-BP-3 (3 $\mu \mathrm{g} / \mathrm{ml})$ for ca. 40 mins. DNA binding dye Hoechst 33342 was used as a positive control (at $14 \mu \mathrm{g} / \mathrm{ml}$ ) and DMSO was used as a negative control. Brightfield and fluorescent images (UV filter set) were captured using a Nikon TE2000S inverted fluorescence microscopy with IPLab scientific imaging software version 3.7 (Scanalytics, Inc., Rockville, USA).

\section{RNA extraction and library preparation:}

Total RNA was extracted using a bacterial RiboPure RNA Purification Kit (AM1925, ThermoFisher Scientific) immediately after samples were collected. In brief, the cells were disrupted mechanically using Zirconia beads, total RNA was then extracted in phenol and purified using glass-fibre filters. Finally, the samples were treated with DNase I according to the manufacturer's instructions. Total RNA was assessed by QuBit@ 2.0 Fluorometer (ThermoFisher Scientific) and the associated Qubit RNA assay (Q32852, ThermoFisher Scientific). RNA integrity was confirmed using an Agilent 2100 Bioanalyzer and the associated RNA 6000 pico kit (Agilent Technologies). Samples containing $4.5 \mu \mathrm{g}$ of total RNA were depleted for ribosomal RNA using a Ribozero rRNA depletion kit (MRZGP126, Cambio), with depletion confirmed by a Bioanalyzer (Agilent). Ion Torrent RNA-Seq library preparation used an lon total RNA-Seq Kit V2 (4475936, ThermoFisher Scientific) with lon xpress RNA- 
Seq BC 01-16 kit barcodes (4475485, ThermoFisher Scientific) as per supplier's instructions.

\section{Sequencing and data analysis:}

The libraries were sequenced using an lon Torrent PGM (ThermoFisher Scientific) and raw data analysis carried out using the associated lon Torrent Suite 5.0.2 (ThermoFisher Scientific). Ion PGM template OT2 kits (4480974, ThermoFisher Scientific) were used for emulsion PCR and enrichment steps, with an lon PGM 200 kit V2 (4482006, ThermoFisher Scientific) for sequencing reactions. Assessment of Ion Sphere Particle quality was undertaken using the Ion Sphere Quality Control Kit (4468656, ThermoFisher Scientific). Triplicate libraries were pooled together to give treated and untreated pools and sequenced initially using lon 314 chips V2 (4482261, ThermoFisher Scientific). Individual libraries were resequenced using a 318 chip V2 (4484354, ThermoFisher Scientific) to provide technical replicates. All sequence data are deposited on the Sequence Read Archive (SRA) under BioProject: PRJNA603263 (http://www.ncbi.nlm.nih.gov/bioproject/603263). FastQ output files were trimmed (quality score 0.02 , discard reads $<50$ bp in length) and RNA-Seq analysis was carried out using CLC Genomics Workbench version 7.5.1 (Qiagen). The transcriptomics analysis was undertaken using the Empirical Analysis of DGE tool in CLC, with default parameters. The significance of gene expression between the treated and non-treated samples was assessed using Bonferroni adjusted p-value $(<0.05)$ with over two-fold change in expression. Gene comparisons were made using Venn diagrams.

\section{qRT-PCR:}

Duplicate samples of total RNA $(1 \mu \mathrm{g})$ were reverse-transcribed using a qPCRBIO cDNA synthesis kit (PB30.11-02, PCR Biosystems) according to manufacturer's 
instructions together with two negative controls (one without reverse transcriptase and another without RNA template). The amount of synthesised cDNA was determined using the QuantiFluor ssDNA system (Promega) with a Qubitß 2.0 Fluorometer (ThermoFisher Scientific) and the samples were stored at $-20^{\circ} \mathrm{C}$. Primers (Supplementary Table 1) were designed using Primer3 version 0.4 .0 software $[13,14]$ and their concentrations were optimised to decrease primer dimer formation. Amplification reactions were carried out using a 2x qPCRBIO SyGreen Mix Lo-ROX (PB20.11, PCRBiosystems) according to manufacturer's instructions with $1 \mu$ l of cDNA as template. The reactions were run on a Corbett Research 6000 instrument. Amplification efficiency and linearity were determined using a dilution series of DNA. Data analysis was performed on Corbett Rotor Gene 6000 software, Microsoft Office Excel and Minitab statistics package.

\section{Phenotypic microarray (PM) analysis:}

Biolog Phenotype MicroArray metabolic panels (PM1, PM2A, PM3B) were used to determine the effect of MGB-BP-3 on growth of $S$. aureus NCTC8325 on single carbon or nitrogen sources. Three dilutions of MGB-BP-3 were tested $(0.5 \times \mathrm{MIC}, 0.25 \times \mathrm{MIC}$, $0.125 \times$ MIC). Biolog chemosensitivity panels (PM11C, PM12B) were used in combination with MGB-BP-3 (0.5 x MIC) to evaluate potential synergy between MGBBP-3 and other antibiotics. Standard Biolog protocols were used with some variances: sodium pyruvate $(5 \mathrm{mM}$, Fisher) was used instead of glucose for PM3B, PM11C and PM12B. Cells were first grown to $\mathrm{OD}_{600}$ of $0.3-0.5$ and then diluted to $\mathrm{OD}_{600} 0.03$ at inoculation. The various dye mixes were tested and dye mix D was selected. All plates were incubated in the OmniLog instrument (Biolog, Inc. USA) at $37^{\circ} \mathrm{C}$ for 48 hours. Growth data were recorded every 15 minutes and analysed with OmniLog software Parametric v1.3 and Kinetic v1.3 (Biolog, Inc. USA). 


\section{Melting curve analysis of dsDNA with MGB-BP-3:}

Three DNA-fragments (70-90 bp long) were amplified by PCR using a standard benchtop PCR machine. The PCR reactions contained S. aureus NCTC8325 gDNA as a template, primers (Supplementary Table 1) and GoTaq ${ }^{\circledR}$ G2 Flexi DNA polymerase (M7801, Promega). Resulting PCR products were purified on columns (Isolate II PCR Kit (BIO-52059, Bioline)) that are suitable for >50 bp DNA fragments. The purified DNA fragments were then mixed with $9 \mu \mathrm{g} / \mathrm{ml}$ of MGB-BP-3 in water, and the mixture incubated for $15 \mathrm{~min}$ in the dark at room temperature before adding 1:1 volume of ready-made PCR mix that contained an intercalating dye (qPCRBIO SyGreen Mix, PB20.11-05, PCR Biosystems), known not to interfere with PCR. Dissociation-characteristics of dsDNA with MGB-BP-3 were measured and the melting curve analysis was performed by raising temperatures sequentially from $50^{\circ} \mathrm{C}$ to $99^{\circ} \mathrm{C}$ using a Rotor-Gene 6000 qPCR machine (RCorbett). Drug-free DNA was used as a control. Statistical significance was assessed by student t-test $(n=3)$.

\section{Electrophoretic Mobility-Shift assays (EMSA):}

The pdnaD and pmraY promoter fragments were synthesized by Integrated DNA Technologies (Leuven, Belgium) and sub-cloned into plasmid pSR, as a source of DNA fragments for EMSA and footprinting experiments [15]. EMSA was carried out essentially as detailed by Rossiter et al. [16]. Purified Aatll-HindIII promoter fragments were end-labelled with [ $\left.\gamma^{-32} \mathrm{P}\right]-\mathrm{ATP}$ and approximately $0.2 \mathrm{nM}$ of each fragment was incubated with varying amounts of MGB-BP-3. The final reaction volume $(10 \mu \mathrm{l})$ contained HEPES glutamate buffer ( $\mathrm{pH}$ 8.0, $20 \mathrm{mM}$ HEPES, $5 \mathrm{mM} \mathrm{MgCl}$, $50 \mathrm{mM}$ potassium glutamate, $1 \mathrm{mM}$ DTT, $5 \%(\mathrm{v} / \mathrm{v})$ glycerol, $0.5 \mathrm{mg} / \mathrm{ml}$ BSA) containing 25 $\mu \mathrm{g} / \mathrm{ml}$ herring sperm DNA. MGB-BP-3 was incubated with labelled DNA fragments at 
room temperature for 15 minutes, after which samples were loaded directly onto a running $6 \%(\mathrm{w} / \mathrm{v})$ polyacrylamide gel $(12 \mathrm{v} / \mathrm{cm})$, containing $2 \%(\mathrm{v} / \mathrm{v})$ glycerol and 0.25 x TBE (Tris/ borate/ EDTA buffer). Gels were analysed using a Bio-Rad Personal Molecular Imager (PMI) and Quantity One software (Bio-Rad).

\section{DNase I and permanganate footprinting:}

DNase I and potassium permanganate footprinting experiments were performed on ${ }^{32} \mathrm{P}$-end-labelled Aatll-BamHI promoter fragments, using protocols described previously $[17,18]$. Each reaction mix $(20 \mu \mathrm{l})$ contained approximately $1.35 \mathrm{nM}$ template DNA in HEPES glutamate buffer, containing $30 \mu \mathrm{g} / \mathrm{ml}$ herring sperm DNA. DNA fragments were incubated with varying concentrations of MGB-BP-3 for 15 minutes at room temperature before footprinting. For potassium permanganate footprint experiments, herring sperm DNA was omitted from the reaction mixture and either E. coli RNA polymerase $\sigma^{70}$ holoenzyme (Epicentre) or $S$. aureus RNA polymerase $\sigma^{\mathrm{A}}$ holoenzyme [19] were used at a final concentration of $50 \mathrm{nM}$. The products of all footprinting reactions were analysed by denaturing gel electrophoresis and calibrated with Maxam-Gilbert ' $G+A$ ' sequencing reactions of the labelled fragment. Gels were quantified using Bio-Rad PMI and Quantity One software.

\section{Evolution of resistance in the laboratory:}

A single colony of $S$. aureus (ATCC clone 43300) was transferred to $5 \mathrm{ml} \mathrm{L-Broth}$ (LB) and, after overnight incubation at $37^{\circ} \mathrm{C}, 50 \mu \mathrm{l}$ of the culture was used for serial daily passaging (1/1,000 dilution) in $5 \mathrm{ml}$ LB having either MGB-BP-3 $(0.019 \mu \mathrm{g} / \mathrm{ml}, 3$ replicates), rifampicin $(0.4 \mathrm{ng} / \mathrm{ml})$, or no antibiotic (control). After 4 passages (40 generations), concentrations of antibiotics were doubled and passaged daily for 4 
further days (40 generations). Aliquots $(5 \mu \mathrm{l})$ of various $1 / 10$ serial dilutions of the resulting cultures were then spotted in LB-agar plates having either $0.15 \mu \mathrm{g} / \mathrm{ml}$ MGB$\mathrm{BP}-3$, or $4 \mathrm{ng} / \mathrm{ml}$ rifampicin (each corresponding to $2 \mathrm{x} \mathrm{MIC} 80$ ), and plates were incubated overnight at $37^{\circ} \mathrm{C}$.

\section{Results:}

\section{Exposure to MGB-BP-3 elicits significant changes in the $S$. aureus transcriptome}

The minimum inhibitory concentration (MIC) of MGB-BP-3 for S. aureus NCTC8325 was $0.19 \mu \mathrm{g} / \mathrm{ml}$ (Supplementary Data MIC). Using fluorescence microscopy, bacterial cells exposed to MGB-BP-3 showed clear fluorescence with no intracellular localisation (Figure 1b). Growth of $S$. aureus in the presence of a sub-lethal concentration of MGB-BP-3 (0.5 x MIC) was found to be affected for 100 minutes postMGB-BP-3 administration (Figure 1c). Therefore, we decided to perform RNA-Seq experiments at an early time-point (ten minutes) after challenge with MGB-BP-3. This transcriptomic analysis identified 698 transcripts showing significant changes (Supplementary Table 2), some of which were confirmed by quantitative RT-PCR (Supplementary Data qRT-PCR). Previous work by Chaudhuri et al. had identified 351 essential genes for growth and survival of $S$. aureus in laboratory culture [20]. Out of the total of 404 downregulated genes in cultures treated with MGB-BP-3, 62 had been classified as essential, and belonged to a variety of gene ontology categories (Figure 2). 
Further gene ontology analysis of the RNA-Seq data using TIGRFAM protein families [21] identified disruptions in transcription of genes assigned to every Main Role category. Overall, transcription was down-regulated in all categories apart from amino acid biosynthesis, fatty acid and phospholipid metabolism, mobile genetic element functions and transcription (Figures 3 \& 4). Transcription of certain non-essential, amino acid biosynthetic genes was stimulated (Supplementary Table 2). Some of these effects were consistent with downregulation of the arginine repressor (SAOUHSC_01617, argR) and subsequent consequences on its target genes. Genes involved in biosynthesis of molybdopterin were upregulated, whereas various genes involved in menaquinone and ubiquinone biosynthesis were downregulated significantly (Supplementary Table 2). Some essential genes for pantothenate and coenzyme A biosynthesis and for pyridine nucleotide biosynthesis were downregulated significantly.

Over half of the genes associated with biosynthesis and degradation of the murein sacculus and peptidoglycan were down-regulated significantly in the RNA-Seq experiment. (Supplementary Table 2). Reduced expression of essential cell division genes) was also noted while the septation ring formation regulator (SAOUHSC_01827, ezrA) was also repressed. Some genes involved in DNA replication were down-regulated but, by contrast, some genes involved in DNA supercoiling and primosome formation were up-regulated.

Changes such as those described above could reflect either direct interaction of MGBBP-3 at the level of the individual gene (considered in the section on $d n a D$ and mraY promoter regions below), or secondary effects via global regulators. This possibility prompted an assessment of the diverse phenotypes of $S$. aureus when challenged with MGB-BP-3. 


\section{Conditional essentiality allows correlation between phenotype and} transcriptotype.

Omnilog colorimetric redox phenoarrays were used to directly assess the effect of MGB-BP-3 on metabolism. This approach has the advantage of testing conditional essentiality of down-regulated transcripts in the presence of a sole carbon or nitrogen source. Out of the 191 carbon and 95 nitrogen sources tested and in the absence of MGB-BP-3, S. aureus NCTC8325 could utilise 63 carbon and 23 sole nitrogen sources (Supplementary Data; Phenoarrays).

When challenged with sub-MIC levels of MGB-BP-3, S. aureus showed several regimes concerning the ability to utilise individual substrates for growth, and in a dosedependent response $(0.5 \times$ MIC, $0.25 \times$ MIC, $0.125 \times$ MIC of MGB-BP-3;

Supplementary Data Phenoarrays). Growth on thymidine, glutamine, glycine and arginine as a sole carbon source was affected by MGB-BP-3, whereas growth on ornithine as a single carbon source was not. This was consistent with the results of RNA-Seq (see Discussion).

\section{Melting curves of MGB-BP-3 bound to dsDNA reveals upstream binding sites}

To further identify putative MGB-BP-3 binding sites, upstream regions of two genes shown to be repressed by RNA-Seq (dnaD (SAOUHSC_01470) and mraY (SAOUHSC_01146)) were taken forward for melt analysis after being randomly selected from the ten most down-regulated transcripts. MGB-BP-3 would be expected to bind to such a DNA fragment, stabilise its structure, and increase its melting temperature. The genome locations of both genes showed no other genes located directly upstream from the start of the gene of interest. A GC-rich (GC-content $50 \%$ ) internal region of gyrA (SAOUHSC_00006) was used as comparative control. The 
melting temperature of each DNA fragment was increased in the presence of MGBBP-3, indicating binding of the antibiotic to these AT-rich regions (GC-content of 25$26 \%$ ) (Figure 5). By contrast, the melting temperature of the control fragment (gyrA internal region) was unchanged in the presence of MGB-BP-3.

\section{MGB-BP-3 binds to the $d n a D$ and mraY promoter regions to interfere with transcriptional initiation.}

DNA melt curves indicated that MGB-BP-3 binds to DNA with some specificity. To examine this further, EMSA assays investigated the binding of MGB-BP-3 to endlabelled DNA fragments, which carried the $d n a D$ and $r m a Y$ promoter regions ( $p d n a D$ and pmraY) (Figure 6). These were chosen as representative of genes that were shown to be down-regulated on challenge with MGB-BP-3 by RNA-Seq and qPCR.

MGB-BP-3 is a small molecule (MW $746 \mathrm{Da}$ ). A ladder of fragments with altered mobility was observed for each, indicating that each promoter fragment carried multiple binding sites for MGB-BP-3 (Figure 7). Thus, to pinpoint these MGB-BP-3 binding sites at high resolution, DNase I footprinting was used (Figure 8). For each promoter fragment, discrete high affinity binding sites were observed at low concentrations of MGB-BP-3, whilst additional protections from DNase I were observed as the concentration of antibiotic was increased. In particular, high affinity binding sites for MGB-BP-3 correlated with regions of $A / T$ richness, close to the experimentally determined transcription start sites and overlapping the predicted -10 elements of each promoter (Figures 6 and 8) [27-29]. As positioning of such high affinity binding sites for MGB-BP-3 could interfere with transcriptional initiation, potassium permanganate footprinting was used to examine promoter isomerisation by RNA polymerase at each promoter. Single-stranded DNA, generated by DNA melting 
during transcriptional initiation, is sensitive to modification by permanganate, which can be detected by gel electrophoresis $[18,30]$. In the absence of MGB-BP-3, both $E$. coli and S. aureus RNA polymerase holoenzyme could recognise pdnaD and pmraY, unwinding the DNA surrounding the transcription start site and each -10 promoter element. However, in the presence of MGB-BP-3, unwinding around the promoter was completely inhibited (Figures 9 and 10), confirming that MGB-BP-3 prevents transcription initiation at $p d n a D$ and $p m r a Y$ by occluding the promoter region and preventing RNA polymerase isomerisation.

\section{Can S. aureus evolve to be resistant to MGB-BP-3?}

As MGB-BP-3 binds to multiple sites in the bacterial genome, with consequential reduction in transcription of essential genes, a great number of mutations would have to occur within a short time period to result in resistance to this antibiotic. This contrasts with other antibiotics such as rifampicin, which bind to a single target, such that a single genetic mutation is sufficient to confer resistance. Indeed, after serial passaging of three independent populations of $S$. aureus at sub-MIC80 concentrations of MGBBP-3 (up to $0.5 x \mathrm{MIC} 80$ ) for 80 generations, no resistant clone was isolated. By contrast, serial passaging for the same period at sub-MIC80 concentrations of rifampicin (up to $0.4 \times \mathrm{MIC} 80$ ), resistant colonies were identified even at the lowest spotted concentration (corresponding to $\mathrm{OD}_{600} 10^{-8}$, Supplementary Data; Resistance). In a second experiment, a population of $S$. aureus was passaged at $0.66 x$ MIC80 of MGB-BP-3 for 280 generations, but no resistance was observed (data not shown). 


\section{Discussion:}

DNA minor groove-binding drugs have shown promise in the treatment of a variety of diseases [31]. Amongst these, novel antibiotic MGB-BP-3 is in development for treatment of Clostridioides difficile infections and has completed Phase II clinical trials successfully. Here, S. aureus was used as a model organism to study MGBBP-3 mode of action, since much of the preliminary work for the MGB-BP-3 development program had already been done with this organism. Moreover, this choice simplified the growth conditions for the Biolog phenotypic array work.

Transcriptomics identified 62 essential genes that were repressed in the presence of this DNA-binding antibiotic (Figure 2). Transcriptional changes in seven of these genes (argH, cdd, citC, gapA, hup, mvaK2 and pyrF) was confirmed independently by qRT-PCR. Several genes with regulatory functions that could account for some of the changes seen in the RNA-Seq data had expression altered significantly on exposure to MGB-BP-3. (Supplementary Table 2). For instance, anti-anti-sigma factor rsbV (SAOUHSC_02300) was repressed whereas RNA polymerase sigma factor RpoD coded by sigA (SAOUHSC_01662) was stimulated. Moreover, twocomponent systems such as walKR (SAOUHSC_00021 and SAOUHSC_00020) and phoPR (SAOUHSC_01800 and SAOUHSC_01799), together with glutamine synthetase repressor $g \ln R$ (SAOUHSC_01285), DNA-binding response regulator srrA (SAOUHSC_01586), transcriptional regulator nrdR (SAOUHSC_01793) and transcription of LexA repressor (SAOUHSC_01333, lexA) were down-regulated significantly.

Microtiter plate-based phenoarrays offer an alternative strategy to investigate challenge of bacterial cells by MGB-BP-3, illustrating the conditional essentiality 
effects of the antibiotic and providing data (Supplementary Data Phenoarrays) to compare with the transcriptomic response. Thus, none of the genes for ornithine metabolism (SAOUHSC_00076, SAOUHSC_00148, SAOUHSC_00150, SAOUHSC_00894,SAOUHSC_01128,SAOUHSC_02967, SAOUHSC_02968) had significantly altered expression profiles on challenge by MGB-BP-3, consistent with the data from the phenotypic arrays. Although arginine is a precursor of ornithine [25], its metabolism was affected negatively on challenge by MGB-BP-3 in a dose dependent manner. Transcriptomics revealed that expression of ahrC (SAOUHSC_01617) was significantly downregulated (by 6-fold) on exposure to MGB-BP-3. AhrC acts as a repressor of arginine biosynthesis and an activator of the arginine catabolic pathway in $B$. subtilis [26]. Thus down-regulation of arginine catabolism directly could explain the differences seen in response to MGB-BP-3 for growth on either arginine or ornithine as a single carbon source. Further correlations between the transcriptomic data and phenotypic arrays reinforced the multiplicity of effects on the bacterial cells on challenge with MGB-BP-3. Taken together, our data supports the hypothesis that MGB-BP-3 binds to and inhibits multiple essential promoters on the $S$. aureus chromosome.

Reflecting the current annotation status of $S$. aureus, genes encoding hypothetical proteins and proteins with unknown function were the largest category in the transcriptomic data that showed a general trend of transcriptional repression. By contrast, hypothetical protein SAOUHSC_00420 was the most upregulated gene (203fold) in the RNA-Seq dataset (Figure 4). It is predicted to encode a sodium-dependent transporter that has been implicated in extracellular DNA release during biofilm formation in S. aureus [24]. The second most enhanced gene SAOUHSC_00880 (53fold change) was a hypothetical protein, also assigned to the category of transport and 
binding proteins. A further 7 out of 16 of the most upregulated genes belonged to this category, which may reflect a generalised antibiotic stress response.

Direct inhibition of transcription at individual gene loci by was investigated further by focussing on two essential genes as exemplars, dnaD (SAOUHSC_01470) and mraY(SAOUHSC_01146). DNA melt curves demonstrated binding of MGB-BP-3 to upstream regions of these genes (Figure 5), which was confirmed by EMSA (Figure 7). Much higher resolution of MGB-BP-3 binding upstream of these genes was determined with DNAse I footprinting assays (Figures 6 and 8) demonstrating that high affinity binding sites for MGB-BP-3 overlap both the $d n a D$ and mraY promoters. The presence of multiple MGB-BP-3 binding sites upstream of both $d n a D$ and $m r a Y$ may explain the strength of the inhibitory effect at these particular promoters (Figures 6 and 8). Permanganate footprinting of these promoters in the presence of purified RNA polymerase (RNAP) from both E. coli and $S$. aureus demonstrated that MGB-BP-3 binding to the -10 element inhibited the isomerisation of the promoter by RNAP holoenzyme (core polymerase plus SigA, Figures 6, 9 and 10). Specificity of transcription from promoters such as $d n a D$ and mraY is conferred by the SigA subunit of RNAP. Thus, it has been demonstrated that MGB-BP-3 binds to certain SigA-dependent promoter regions, preventing transcription of these genes. This is almost certainly not the sole mechanism of action of MGB-BP-3 since transcription is not the only essential protein-DNA interaction, but is sufficient across the various target genes to explain the catastrophic death on the bacterial cells on challenge with MGB-BP-3.

Microbial drug resistance has become a global health problem and the need to bring new antibiotics to the market is increasing [32]. Resistance against new drugs can develop within the first couple of years of the drug entering the market [33]. Our data 
suggests that MGB-BP-3 binds to multiple sites on $S$. aureus chromosome, making it less likely for resistance to evolve by drug target mutation. To test this hypothesis, laboratory-directed evolution experiments using sub-inhibitory concentrations of MGB-BP-3 showed no resistance in S. aureus. In contrast, resistance to the single target RNA-polymerase inhibitor rifampicin arose rapidly (Supplementary Data; Resistance).

In summary, a novel mode of action for MGB-BP-3 against $S$. aureus has been demonstrated by thorough investigation of two exemplar drug-binding sites on the $S$. aureus chromosome. RNA-Seq analysis revealed a total of 698 transcripts with drug altered expression profiles. It is, therefore, highly likely that there are further multiple MGB-BP-3 binding sites on the $S$. aureus chromosome. Further analysis of DNA binding site sequences combined with rational design of other antibiotic MGBs could provide a powerful methodology for new drug development.

\section{References:}

1. Barrett, M. P., Gemmell, C. G. \& Suckling, C. J. Minor groove binders as antiinfective agents. Pharmacol. Ther. 139, 12-23 (2013).

2. Ross, W., Ernst, A. \& Gourse, R. L. Fine structure of E. coli RNA polymerasepromoter interactions: alpha subunit binding to the UP element minor groove. Genes Dev. 15, 491-506 (2001).

3. Cai, X., Gray, P. J., Jr. \& Von Hoff, D. D. DNA minor groove binders: back in the groove. Cancer Treat. Rev. 35, 437-450 (2009). 
4. Puschendorf, B. et al. Studies on the effect of distamycin A on the DNA dependent RNA polymerase system. Biochem. Biophys. Res. Commun. 43, 617-624 (1971).

5. Taylor, A., Webster, K. A., Gustafson, T. A. \& Kedes, L. The anti-cancer agent distamycin A displaces essential transcription factors and selectively inhibits myogenic differentiation. Mol. Cell. Biochem. 169, 61-72 (1997).

6. Anthony, N. G. et al. Antimicrobial lexitropsins containing amide, amidine, and alkene linking groups. J. Med. Chem. 50, 6116-6125 (2007).

7. Hlaka, L. et al. Evaluation of minor groove binders (MGBs) as novel antimycobacterial agents and the effect of using non-ionic surfactant vesicles as a delivery system to improve their efficacy. J. Antimicrob. Chemother. 72, 33343341 (2017).

8. Scott, F. J. et al. Selective anti-malarial minor groove binders. Bioorg. Med. Chem. Lett. 26, 3326-3329 (2016).

9. Scott, F. J. et al. An evaluation of Minor Groove Binders as anti-Trypanosoma brucei brucei therapeutics. Eur. J. Med. Chem. 116, 116-125 (2016).

10. Scott, F. J. et al. An evaluation of Minor Groove Binders as anti-fungal and anti-mycobacterial therapeutics. Eur. J. Med. Chem. 136, 561-572 (2017). 
11. Scott, F. J. et al. An evaluation of Minor Groove Binders as anti-lung cancer therapeutics. Bioorg. Med. Chem. Lett. 26, 3478-3486 (2016).

12. Anthony, N. G. et al. Short lexitropsin that recognizes the DNA minor groove at 5'-ACTAGT-3': understanding the role of isopropyl-thiazole. J. Am. Chem. Soc. 126, 11338-11349 (2004).

13. Koressaar, T. \& Remm, M. Enhancements and modifications of primer design program Primer3. Bioinformatics 23, 1289-1291 (2007).

14. Untergasser, A. et al. Primer3--new capabilities and interfaces. Nucleic Acids Res. 40, e115 (2012).

15. Kolb, A., Kotlarz, D., Kusano, S. \& Ishihama, A. Selectivity of the Escherichia coli RNA polymerase E sigma 38 for overlapping promoters and ability to support CRP activation. Nucleic Acids Res. 23, 819-826 (1995).

16. Rossiter, A. E. et al. Expression of different bacterial cytotoxins is controlled by two global transcription factors, CRP and Fis, that co-operate in a sharedrecruitment mechanism. Biochem. J. 466, 323-335 (2015).

17. Browning, D. F. et al. The Escherichia coli K-12 NarL and NarP proteins insulate the nrf promoter from the effects of integration host factor. J. Bacteriol. 188, 7449-7456 (2006). 
18. Squire, D. J. et al. Competition between NarL-dependent activation and Fisdependent repression controls expression from the Escherichia coli yeaR and ogt promoters. Biochem. J. 420, 249-257 (2009).

19. Reynolds, J. \& Wigneshweraraj, S. Molecular insights into the control of transcription initiation at the Staphylococcus aureus agr operon. J. Mol. Biol. 412, 862-881 (2011).

20. Chaudhuri, R. R. et al. Comprehensive identification of essential Staphylococcus aureus genes using Transposon-Mediated Differential Hybridisation (TMDH). BMC Genomics 10, 291 (2009).

21. Fuchs, S. et al. AureoWiki The repository of the Staphylococcus aureus research and annotation community. Int. J. Med. Microbiol. 308, 558-568 (2018).

22. Smits, W. K., Merrikh, H., Bonilla, C. Y. \& Grossman, A. D. Primosomal proteins DnaD and DnaB are recruited to chromosomal regions bound by DnaA in Bacillus subtilis. J. Bacteriol. 193, 640-648 (2011).

23. Huang, Y. H., Lien, Y., Huang, C. C. \& Huang, C. Y. Characterization of Staphylococcus aureus Primosomal DnaD Protein: Highly Conserved CTerminal Region Is Crucial for ssDNA and PriA Helicase Binding but Not for DnaA Protein-Binding and Self-Tetramerization. PLoS One 11, e0157593 (2016). 
24. DeFrancesco, A. S. et al. Genome-wide screen for genes involved in eDNA release during biofilm formation by Staphylococcus aureus. Proc. Natl. Acad. Sci. U. S. A. 114, E5969-E5978 (2017).

25. Nuxoll, A. S. et al. CcpA regulates arginine biosynthesis in Staphylococcus aureus through repression of proline catabolism. PLoS Pathog. 8, e1003033 (2012).

26. Miller, C. M., Baumberg, S. \& Stockley, P. G. Operator interactions by the Bacillus subtilis arginine repressor/activator, AhrC: novel positioning and DNA-mediated assembly of a transcriptional activator at catabolic sites. Mol. Microbiol. 26, 37-48 (1997).

27. Prados, J., Linder, P. \& Redder, P. TSS-EMOTE, a refined protocol for a more complete and less biased global mapping of transcription start sites in bacterial pathogens. BMC Genomics 17, 849 (2016).

28. Choe, D. et al. Genome-scale analysis of Methicillin-resistant Staphylococcus aureus USA300 reveals a tradeoff between pathogenesis and drug resistance. Sci. Rep. 8, 2215 (2018).

29. Browning, D. F. \& Busby, S. J. Local and global regulation of transcription initiation in bacteria. Nat. Rev. Microbiol. 14, 638-650 (2016).

30. Sasse-Dwight, S. \& Gralla, J. D. Probing co-operative DNA-binding in vivo. The lac O1:O3 interaction. J. Mol. Biol. 202, 107-119 (1988). 
31. Rahman, A., O'Sullivan, P. \& Rozas, I. Recent developments in compounds acting in the DNA minor groove. MedChemComm 10, 26-40 (2019).

32. Theuretzbacher, U. et al. Analysis of the clinical antibacterial and antituberculosis pipeline. Lancet Infect. Dis. 19, e40-e50 (2019).

33. Coates, A. R., Halls, G. \& Hu, Y. Novel classes of antibiotics or more of the same? Br. J. Pharmacol. 163, 184-194 (2011).

\section{Acknowledgements}

LK was supported by BBSRC grant BB/K019600/1 to NPT, ISH and CJS. Work in NPT's laboratory is also supported by BBSRC grants BB/V509243/1 and BB/S507106/1. KL was supported by CSO grant TCS/16/24 to ISH, CJS and NPT. DFB was supported by BBSRC grant BB/R017689/1. We thank Ramesh Wigneshweraraj and Lynn Burchell for kindly providing purified S. aureus core RNA polymerase and $\sigma^{\mathrm{A}}$ protein.

\section{Author Contributions}

NPT conceived all experiments, LK conceived and performed all microscopy, RNAsequencing, qRT-PCR, melting analysis and phenotypic microarray experiments, DFB conceived and performed all the EMSA, DNase I and permanganate footprinting experiments, $\mathrm{KL}$ performed evolution of resistance experiment and TS performed independent growth studies using single carbon source, LK and NPT 
analysed data and wrote the draft manuscript. DFB, KL, ISH and CJS analysed data and contributed to the manuscript. NPT, ISH and CJS acquired funding.

\section{Competing Interests statement}

The authors declare no competing interests.

\section{Figures}

a

b

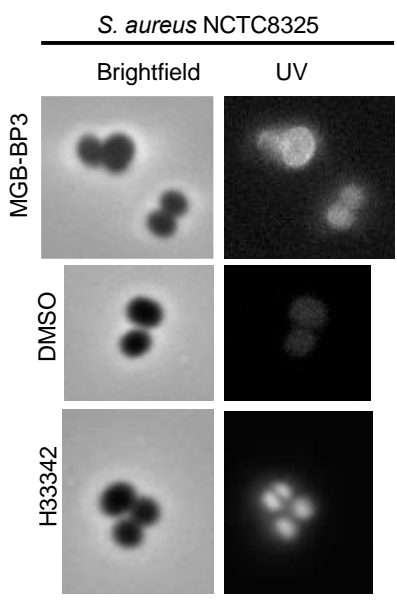

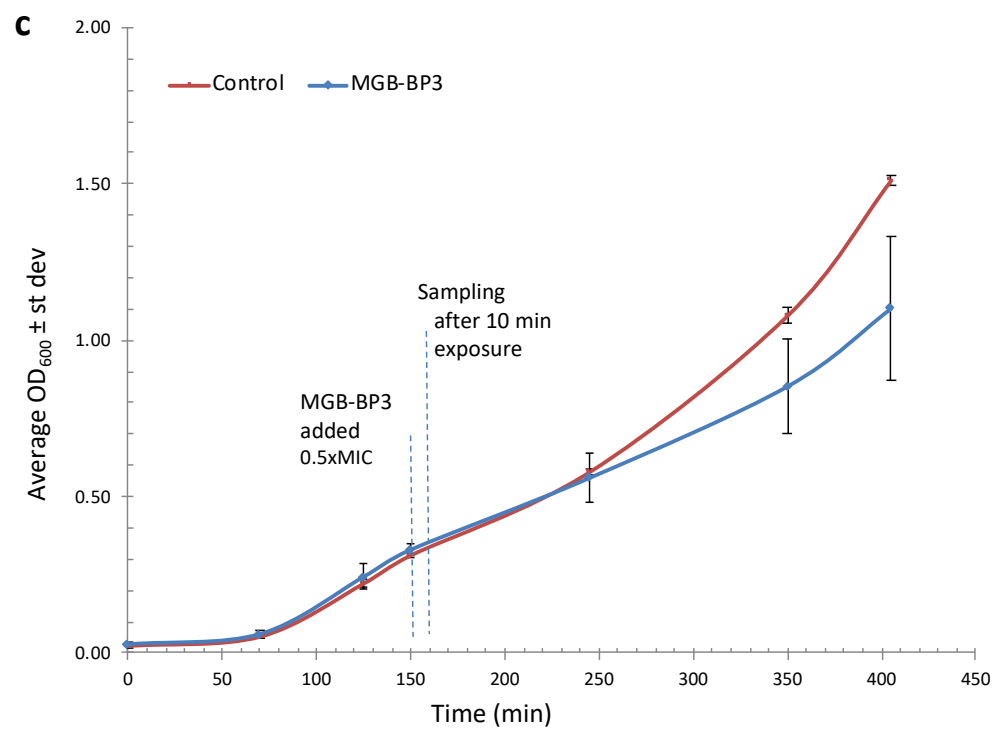

Figure 1: Sub-lethal exposure of $S$. aureus to MGB-BP-3. a. Structure of MGB-BP-3.

b. Microscopy images showing binding of MGB-BP-3 to $S$. aureus cells under UV filter set. DNA binding dye, H33342, used as a positive control and DMSO as a negative control. c. S. aureus NCTC8325 growth, as measured by OD600 MGB-BP-3 $(0.5 \times \mathrm{MIC})$ treated and untreated (control) cultures. Cells were harvested for RNASeq experiment $10 \mathrm{~min}$ after exposure. Error bars, s.d., $n=3$ 


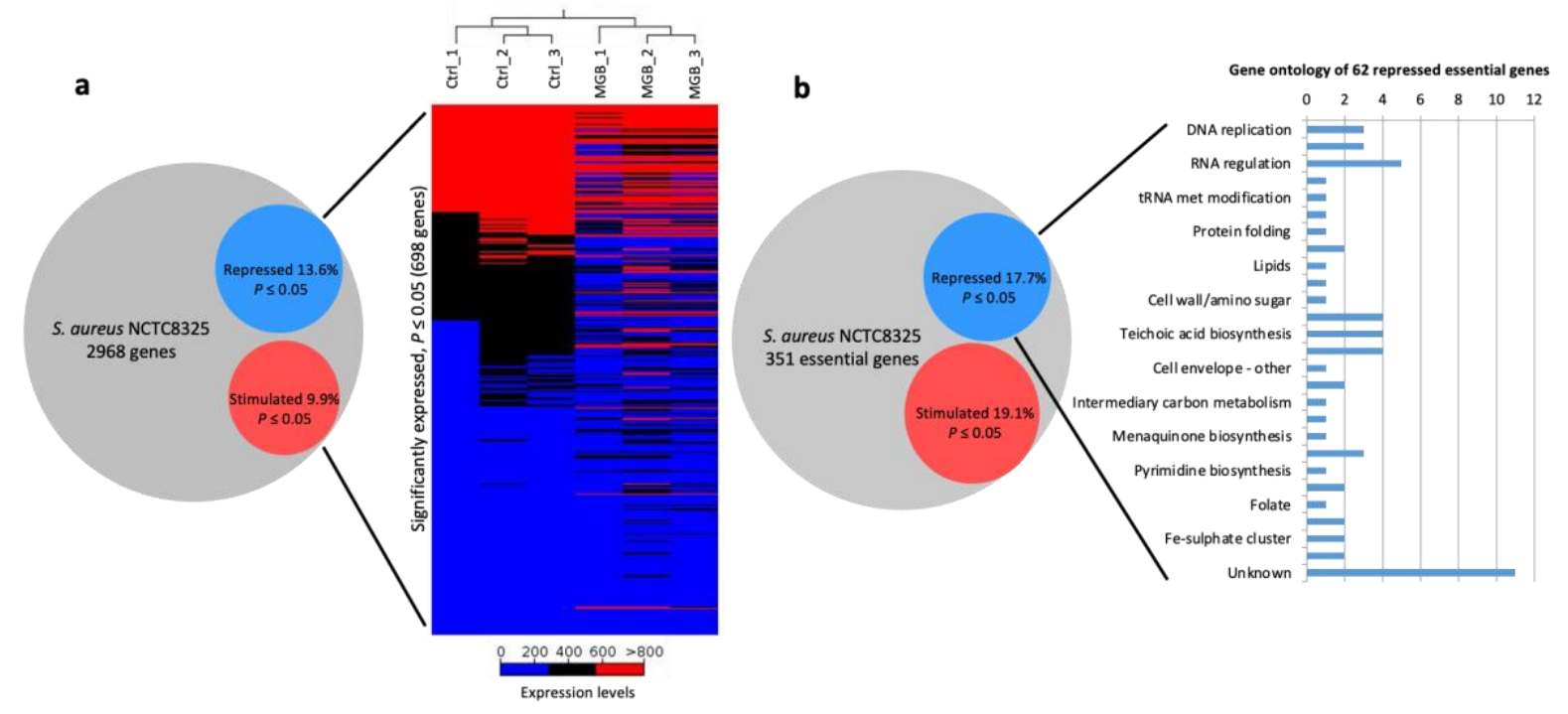

Figure 2: MGB-BP-3 induced transcriptional changes to S. aureus NCTC8325 transcriptome on challenge with $0.095 \mu \mathrm{g} / \mathrm{ml}$ MGB-BP-3 (0.5 X MIC) a. Venn diagram of RNA-Seq Bonferroni corrected $p$-values $(<0.05)$ and a heat map showing hierarchical clustering of the six RNA-Seq samples $(3 \times$ ctrl and $3 \times$ drug treated) with a total of 698 significantly expressed genes. b. Gene ontology of 62 essential $S$. aureus NCTC8325 genes that were identified in RNA-Seq experiment to be downregulated on challenge with MGB-BP-3. 


\begin{tabular}{|l|c|c|c|}
\hline \multicolumn{1}{|c|}{ Main role } & $\begin{array}{c}\text { Total no. } \\
\text { of genes } \\
\text { in each } \\
\text { category }\end{array}$ & $\begin{array}{c}\text { Percentage of genes } \\
\text { differentially } \\
\text { regulated }\end{array}$ \\
\cline { 3 - 4 } & Stimulated & Repressed \\
\hline Amino acid biosynthesis & 74 & 12.2 & 6.8 \\
\hline Biosynthesis of cofactors, prosthetic groups, and carriers & 120 & 12.5 & 15.0 \\
\hline Cell envelope & 72 & 16.7 & 23.6 \\
\hline Cellular processes & 142 & 7.0 & 19.0 \\
\hline Central intermediary metabolism & 37 & 10.8 & 21.6 \\
\hline DNA metabolism & 125 & 12.0 & 14.4 \\
\hline Energy metabolism & 146 & 7.5 & 10.3 \\
\hline Fatty acid and phospholipid metabolism & 27 & 37.0 & 7.4 \\
\hline Mobile and extrachromosomal element functions & 45 & 11.1 & 6.7 \\
\hline Protein fate & 117 & 8.5 & 13.7 \\
\hline Protein synthesis* & 104 & 8.7 & 12.5 \\
\hline Purines, pyrimidines, nucleosides, and nucleotides & 60 & 10.0 & 10.0 \\
\hline Regulatory functions & 90 & 7.8 & 27.8 \\
\hline Signal transduction & 39 & 2.6 & 35.9 \\
\hline Transcription & 32 & 9.4 & 6.3 \\
\hline Transport and binding proteins & 234 & 12.0 & 16.7 \\
\hline Hypothetical protein/unknown function & 1484 & 8.0 & 13.1 \\
\hline & & & \\
\hline *Excluding ribosomal proteins & & & \\
\hline
\end{tabular}

Figure 3: Gene ontology analysis of the $S$. aureus transcriptome after challenge by MGB-BP-3. The percentage of significantly expressed genes belonging to different TIGRFAM protein families is illustrated. The data excludes ribosomal proteins. 

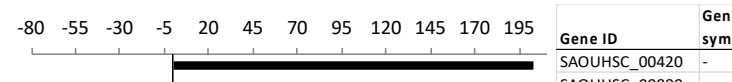
SAOUHSC_00420 SAOUHSC_02184 SAOUHSC_01843 SAOUHSC_00168 SAOUHSC_00302 SAOUHSC_00315 \begin{tabular}{|l|l|}
\hline SAOUHSC_00899 & argG \\
\hline SAOUHSC_03054 & rnpA
\end{tabular} SAOUHSC_01346 SAOUHSC_02187 SAOUHSC_00169 SAOUHSC_02322 SAOUHSC 02108 ftnA SAOUHSC 00928 opp-4A oligopeptide ABC transporter substrate-binding proten SAOUHSC 00691 uppP undecaprenyl pyrophosphate phosphatase SAOUHSC_02473 SAOUHSC 01356 SAOUHSC_01706 SAOUHSC_00740 SAOUHSC_01142 m SAOUHSC_02100 vra SAOUHSC_01144 fts SAOUHSC_A01723 SAOUHSC_01039 SAOUHSC_01143 SAOUHSC_02309 SAOUHSC_02846 SAOUHSC_00824 SAOUHSC_00979 SAOUHSC_02727 SAOUHSC_00593

Gene

TIGRFAM Main Role

hypothetical protein

phi PVL orf 14-like protein

hypothetical protein

hypothetical protein

hypothetical protein

hypothetical protein

argininosuccinate synthase

ycine betaine transporter

K97 family phage protei

Mobile and extrachromosomal element functions

hypothetical protein

transcription antiterminator

hypothetical protein

hypothetical protein

cell division protein Mraz

hypothetical protein

cell division protein

hypothetical protein

hypothetical protein

S-adenosyl-methyltransferase MraW

hypothetical protein

hypothetical protein

hypothetical protein

hypothetical protein

hypothetical protein

hypothetical protein

hypothetical protein

Figure 4: List of genes with the largest fold-changes of the $S$. aureus transcriptome on challenge by MGB-BP-3. The top 10 of genes with the smallest or largest foldchanges are included.

\section{Melt analysis}

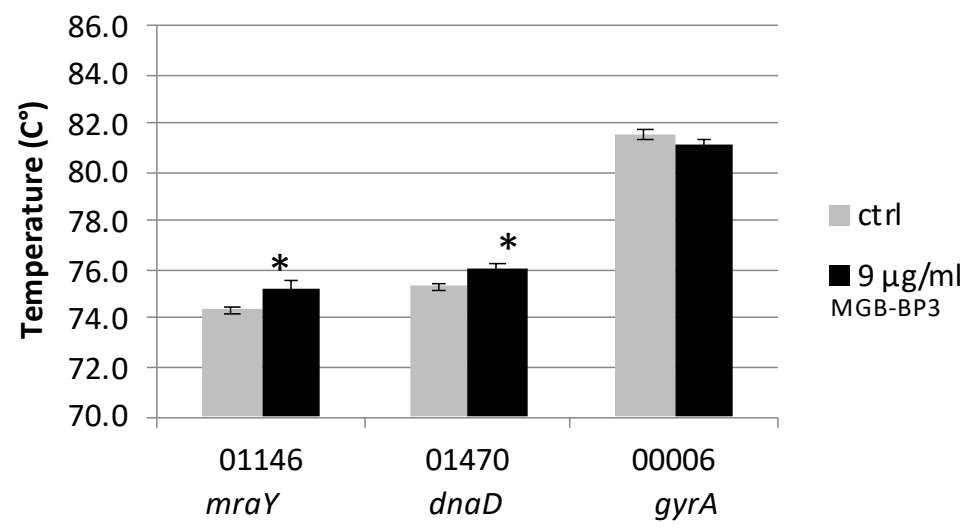

Figure 5: Melt analysis of DNA-MGB-BP-3 $(9 \mu \mathrm{g} / \mathrm{ml})$ complexed with promoter segments of mraY and $d n a D$. An AT-rich internal region of gyrA was used as DNA segment that should have no binding site for MGB-BP-3. Control samples (grey) did not contain MGB-BP-3. Statistical significance $(p \leq 0.05)$ is indicated with an asterisk. Error bars, s.d., $n=3$ 
a

pdnaD

GAАTTCTTAAAАTTGTTTGCTACTAGTTAAATATATTAAG CATTTTA GCGAAAAT TAAAGAAAATGATT TATACTATTAA

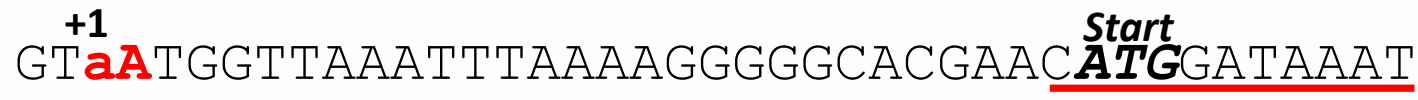
ATCAATTAAAAGCAAGACCTGTAGTGATACGAA $\underline{\text { AAGCTT }}$

b

\section{pmraY}

GAATTCAAAGAAAAATTATAAATTTTATTACAACT $\frac{\mathbf{- 3 5}}{\mathbf{T T} \mathbf{T}}$

TATTTAATTGAAAAATTGATAATATATTAGTوGTTAAAAAA

GTCTGGATTAAGAAGAGGAGATAGTTÄATATTTTTGTATAT

GCGTTATTAGCGCTAGTGATTACATTTGTTTTG $\underline{\text { AGCTT }}$

Figure 6: Organisation of the pdnaD (a) and prmaY (b) promoter regions of $S$. aureus. (+1 and lower case) denotes the experimentally determined transcription start site [27, 28] and the predicted -10 and -35 regions are also shown in bold [29]. The cleavage sites produced by potassium permanganate footprinting are shown in red and bold, whilst the extent of the high affinity MGB-BP-3 binding sites, determined by DNase I footprinting, are underlined in red. The translation start of each gene (ATG) is italicised and bold. The EcoRI and Hindlll sites introduced onto each fragment to facilitate cloning into pSR are shown italicised and underlined. 
a

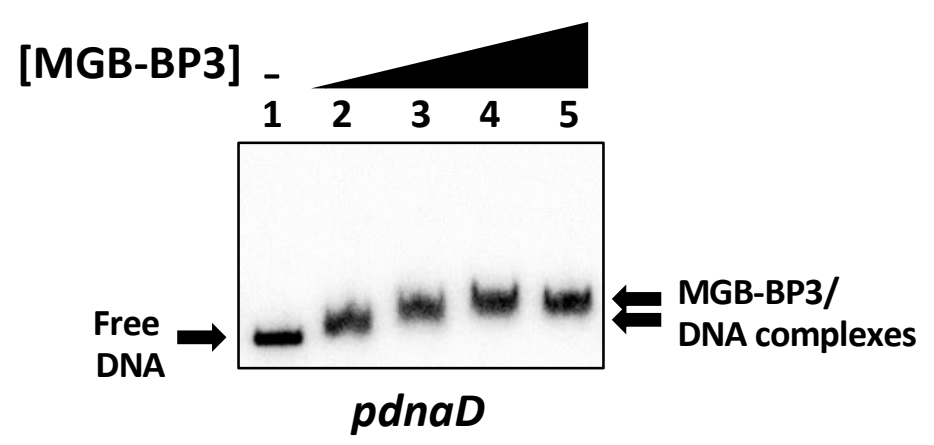

b

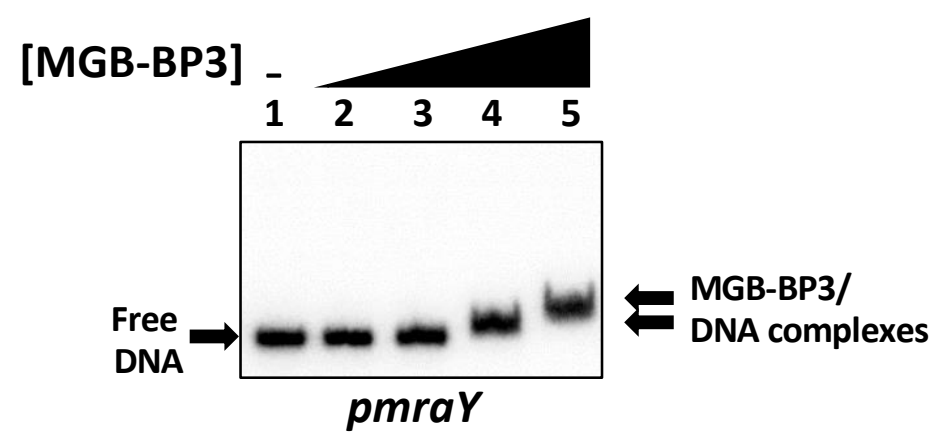

Figure 7: MGB-BP-3 binds to the pdnaD and prmaY S. aureus promoters. EMSA of the (a) pdnaD and (b) pmraY promoter regions with MGB-BP-3. End-labelled AatllHindlll fragments were incubated with increasing concentrations of MGB-BP-3 as follows: lane 1, no MGB-BP-3; lane 2, $1.25 \mu \mathrm{g} / \mathrm{ml}$; lane 3, $2.5 \mu \mathrm{g} / \mathrm{ml}$; lane 4, $5 \mu \mathrm{g} / \mathrm{ml}$; lane $5,10 \mu \mathrm{g} / \mathrm{ml}$. 
a

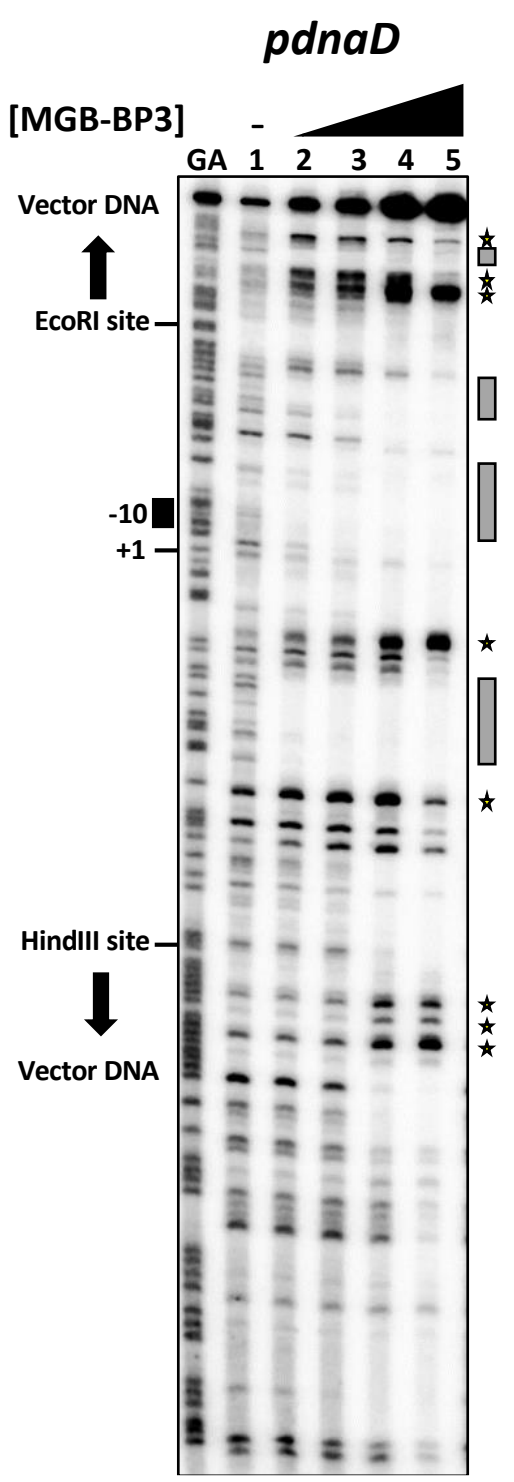

b

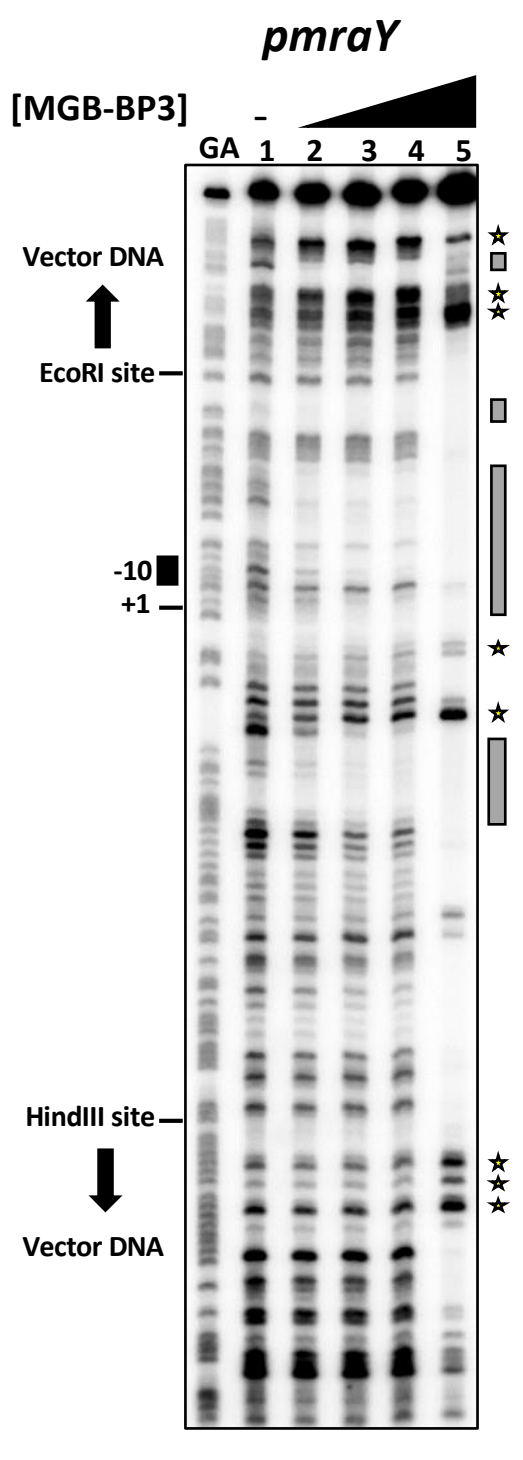

Figure 8: MGB-BP-3 binds to discrete sites within the pdnaD and prmaY S. aureus promoters. DNase I footprinting analysis of the (a) pdnaD and (b) pmraY promoter regions when bound by MGB-BP-3. End-labelled Aatll-BamHI fragments were incubated with increasing concentrations of MGB-BP-3 and subjected to DNase I footprinting. The concentrations of MGB-BP-3 used were as follows: lane 1, no MGBBP-3; lane 2, $1.25 \mu \mathrm{g} / \mathrm{ml}$; lane 3, $2.5 \mu \mathrm{g} / \mathrm{ml}$; lane 4, $5 \mu \mathrm{g} / \mathrm{ml}$; lane 5, $10 \mu \mathrm{g} / \mathrm{ml}$. Gels were calibrated using Maxam-Gilbert ' $G+A$ ' sequencing reactions (lane $G A$ ) and the location of the -10 element and transcription start site $(+1)$ for each promoter is indicated. Regions of high affinity MGB-BP-3 protection are indicated by grey boxes and hypersensitive sites produced by MGB-BP-3 binding are labelled with stars. The locations of the EcoRI and HindIII sites and the pSR vector sequences on each AatllBamHI fragment are also marked. 

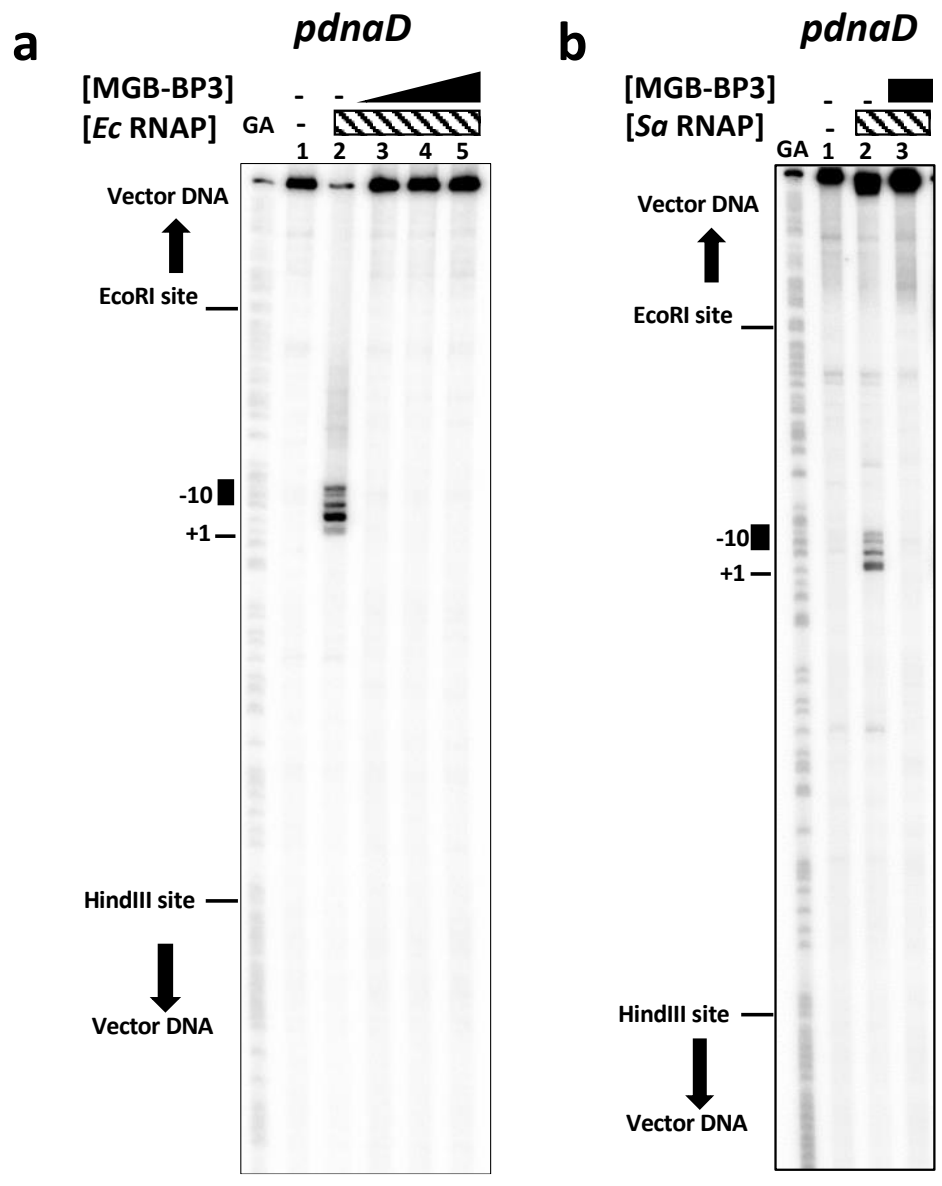

Figure 9: MGB-BP-3 prevents promoter unwinding by both E. coli and S. aureus RNA polymerase holoenzyme at the $p d n a D S$. aureus promoter. Potassium permanganate footprinting analysis of the $p d n a D$ promoter region when bound by MGB-BP-3. (a) End-labelled Aatll-BamHI pdnaD promoter fragment was pre-incubated with MGB-BP3 , challenged with $50 \mathrm{nM} \mathrm{E}$. coli RNA polymerase holoenzyme and subjected to potassium permanganate footprinting. The concentrations of MGB-BP-3 were as follows: lanes 1 and 2, no MGB-BP-3; lane 3, $1.25 \mu \mathrm{g} / \mathrm{ml}$; lane 4, $2.5 \mu \mathrm{g} / \mathrm{ml}$; lane 5, 5 $\mu \mathrm{g} / \mathrm{ml}$. (b) End-labelled Aatll-BamHI pdnaD promoter fragment was pre-incubated with MGB-BP-3, challenged with $50 \mathrm{nM}$ S. aureus RNA polymerase holoenzyme, saturated with $\sigma^{A}$, and subjected to potassium permanganate footprinting. The concentrations of MGB-BP-3 were as follows: lanes 1 and 2, no MGB-BP-3; lane 3, $2.5 \mu \mathrm{g} / \mathrm{ml}$. Gels were calibrated using Maxam-Gilbert ' $G+A$ ' sequencing reactions (lane $G A$ ) and the location of the predicted pdnaD -10 element and experimentally determined transcription start site $(+1)$ is indicated [28]. The positions of the EcoRI and HindIII sites and the pSR vector sequences on each Aatll-BamHI fragment are also marked. 

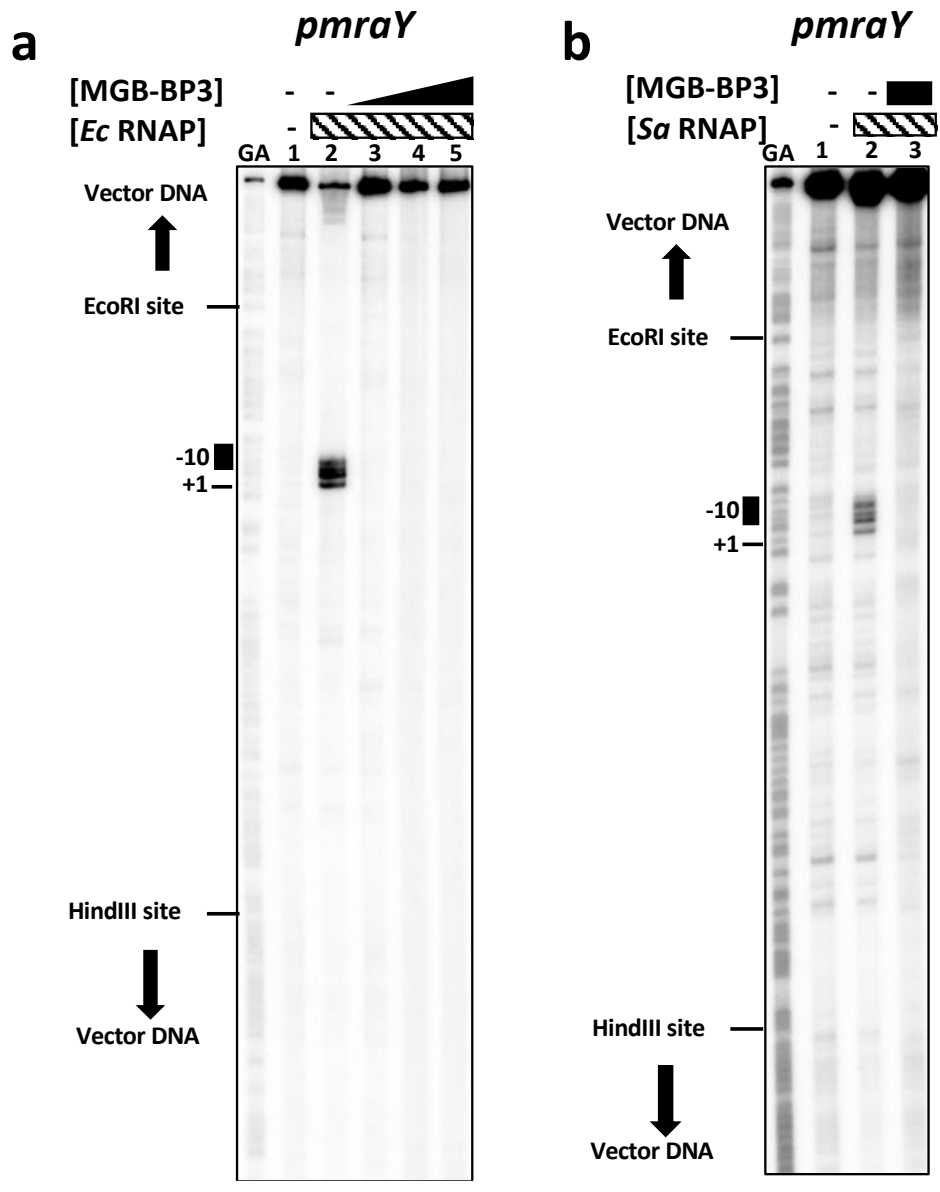

Figure 10: MGB-BP-3 prevents promoter unwinding by both E. coli and S. aureus RNA polymerase holoenzyme at the pmraY $S$. aureus promoter region. Potassium permanganate footprinting analysis of the pmraY promoter region when bound by MGB-BP-3. (a) End-labelled Aatll-BamHI pmraY promoter fragment was preincubated with MGB-BP-3, challenged with $50 \mathrm{nM}$ E. coli RNA polymerase holoenzyme and subjected to potassium permanganate footprinting. The concentrations of MGB-BP-3 were as follows: lanes 1 and 2, no MGB-BP-3; lane 3, $1.25 \mu \mathrm{g} / \mathrm{ml}$; lane 4, $2.5 \mu \mathrm{g} / \mathrm{ml}$; lane 5, $5 \mu \mathrm{g} / \mathrm{ml}$. (b) End-labelled Aatll-BamHI pmraY promoter fragment was pre-incubated with MGB-BP-3, challenged with $50 \mathrm{nM} S$. aureus RNA polymerase holoenzyme, saturated with $\sigma^{\mathrm{A}}$, and subjected to permanganate footprinting. The concentrations of MGB-BP-3 were as follows: lanes 1 and 2, no MGB-BP-3; lane 3, $2.5 \mu \mathrm{g} / \mathrm{ml}$. Gels were calibrated using Maxam-Gilbert ' $G+A$ ' sequencing reactions (lane $G A$ ) and the predicted location of the pmraY -10 element and the experimentally determined transcription start site $(+1)$ is indicated [27]. The positions of the EcoRI and HindIII sites and the pSR vector sequences on each Aatll-BamHI fragment are also marked. 


\section{Supplementary information}

\section{Supplementary Data -MIC. Comparison of the MIC of vancomycin and MGB-BP-3 against $S$. aureus}
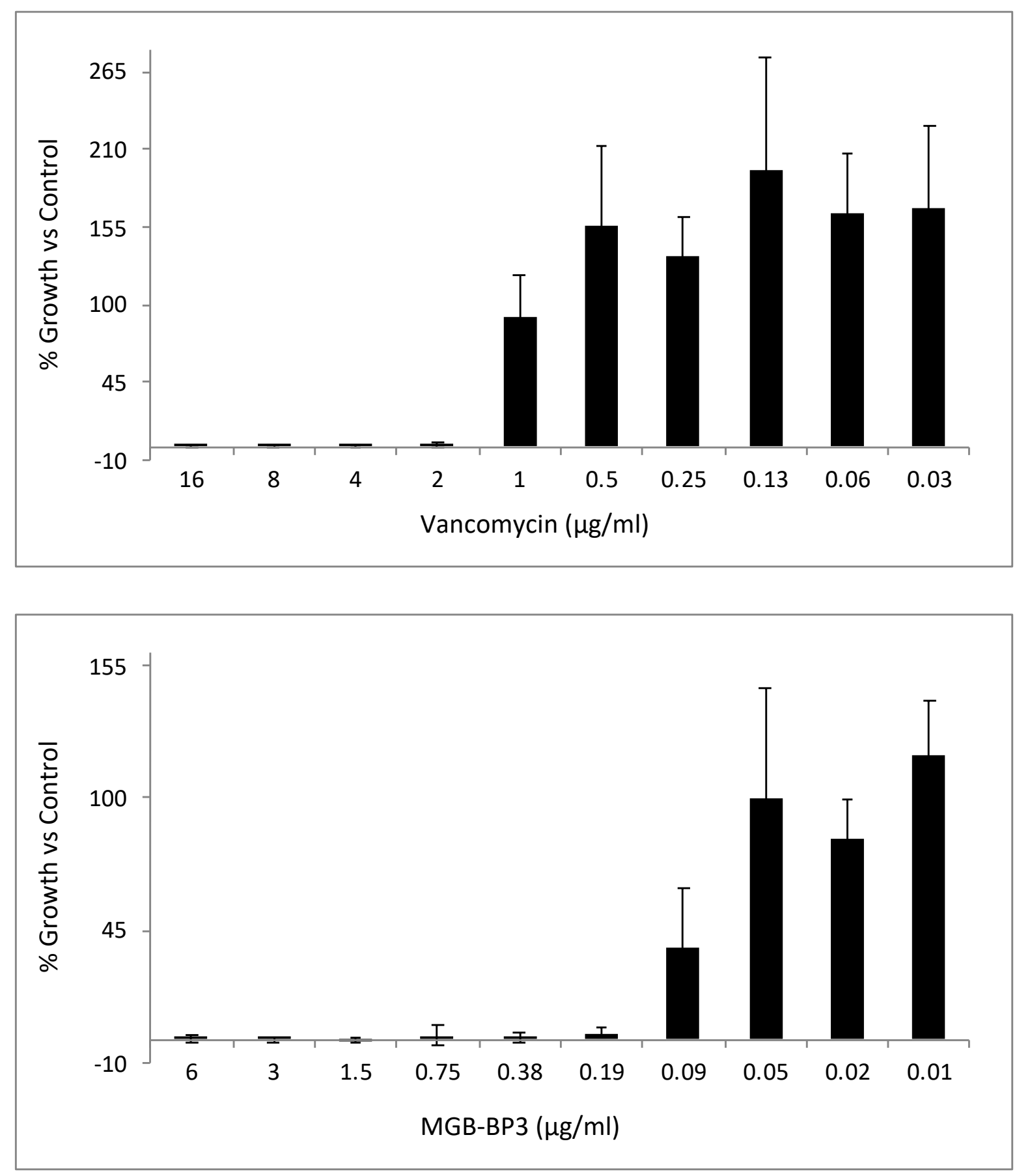


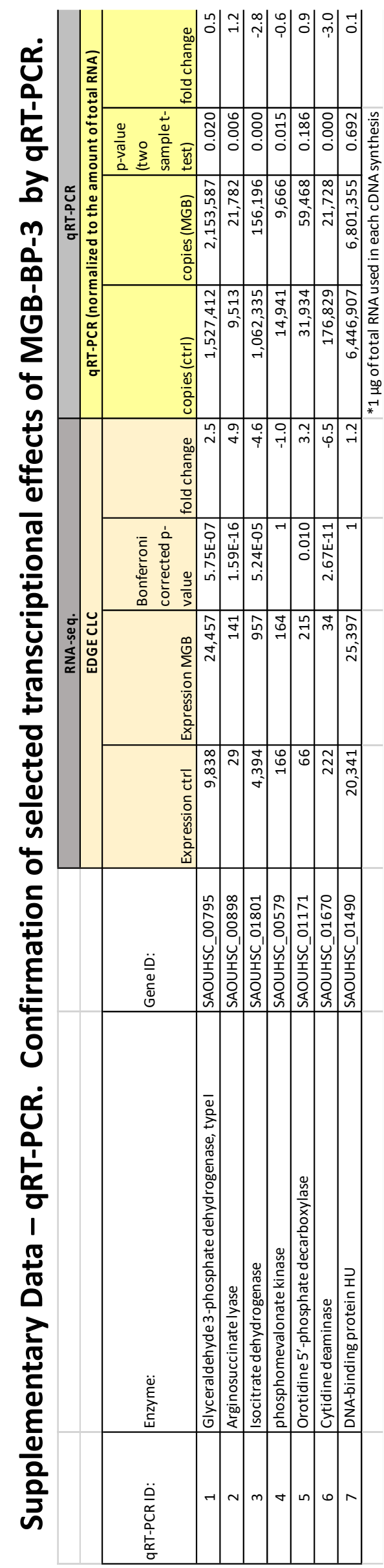




\section{Supplementary Data - Phenoarrays.}

\begin{tabular}{|c|c|c|c|c|c|c|c|c|c|}
\hline \multirow{2}{*}{$\begin{array}{c}\text { Biolog Plate } \\
\text { ID }\end{array}$} & \multicolumn{2}{|c|}{ Well position } & \multicolumn{3}{|c|}{ Biolog compound in well } & \multicolumn{4}{|c|}{$\begin{array}{l}\text { S.aureus NCTC8325 Biolog end point reading at } 47 \text { hour } \\
\text { (background subtracted) }\end{array}$} \\
\hline & row & column & ID & mode & other info & $\begin{array}{l}0.5 \times M I C \\
M G B-B P 3\end{array}$ & $\begin{array}{l}0.25 \times M I C \\
M G B-B P 3\end{array}$ & $\begin{array}{c}0.125 \times M I C \\
M G B-B P 3\end{array}$ & ctrl (DMSO) \\
\hline PM1 & B & 12 & L-glutamic acid & C-source & amino acid & 0 & 182 & 171 & 203 \\
\hline PM2A & $\mathrm{H}$ & 1 & L-ornithine & C-source & amino acid & 175 & 203 & 201 & 202 \\
\hline PM2A & B & 12 & 3-0-b-D-galactopyranosyl-D-arabinose & C-source & carbohydrate & 19 & 199 & 191 & 199 \\
\hline PM1 & G & 12 & L-malic acid & C-source & carboxylic acid & 1 & 179 & 170 & 198 \\
\hline PM1 & A & 3 & $\mathrm{~N}$-acetyl-D-Glucosamine & C-source & carbohydrate & 0 & 144 & 146 & 197 \\
\hline PM1 & G & 1 & glycyl-L-glutamic acid & C-source & amino acid & 0 & 170 & 177 & 197 \\
\hline PM1 & A & 11 & D-mannose & C-source & carbohydrate & 0 & 122 & 137 & 195 \\
\hline PM1 & C & 4 & D-ribose & C-source & carbohydrate & 115 & 177 & 157 & 191 \\
\hline PM1 & $\mathrm{D}$ & 12 & uridine & C-source & carbohydrate & 100 & 178 & 171 & 191 \\
\hline PM1 & B & 7 & D,L-a-glycerol phosphate & \begin{tabular}{|l|}
$\mathrm{C}$-source \\
\end{tabular} & carbohydrate & 77 & 170 & 161 & 190 \\
\hline PM1 & $A$ & 10 & D-trehalose & \begin{tabular}{|l|}
$\mathrm{C}$-source \\
\end{tabular} & carbohydrate & 68 & 114 & 144 & 188 \\
\hline PM1 & C & 12 & thymidine & C-source & carbohydrate & 0 & 69 & 142 & 188 \\
\hline PM2A & $\mathrm{G}$ & 4 & L-arginine & C-source & amino acid & 81 & 133 & 172 & 187 \\
\hline PM1 & $\mathrm{A}$ & 5 & succinic acid & C-source & carboxylic acid & 0 & 165 & 161 & 186 \\
\hline PM1 & B & 11 & D-mannitol & C-source & carbohydrate & 0 & 148 & 136 & 186 \\
\hline PM1 & C & 7 & D-fructose & C-source & carbohydrate & 0 & 135 & 135 & 183 \\
\hline PM1 & $E$ & 1 & L-glutamine & C-source & amino acid & 0 & 86 & 125 & 183 \\
\hline PM1 & $\mathrm{D}$ & 11 & sucrose & C-source & carbohydrate & 30 & 135 & 134 & 182 \\
\hline PM1 & $E$ & 4 & D-fructose-6-phosphate & C-source & carbohydrate & 0 & 163 & 156 & 181 \\
\hline PM1 & D & 6 & a-ketoglutaric acid & C-source & carboxylic acid & 109 & 162 & 152 & 180 \\
\hline PM2A & B & 2 & $\mathrm{~N}$-acetyl-neuraminic acid & C-source & carboxylic acid & 120 & 162 & 161 & 178 \\
\hline PM1 & B & 6 & D-gluconic acid & C-source & carboxylic acid & 0 & 141 & 145 & 177 \\
\hline PM1 & $\mathrm{D}$ & 9 & a-D-lactose & C-source & carbohydrate & 7 & 126 & 116 & 177 \\
\hline PM1 & $\mathrm{C}$ & 1 & D-glucose-6-phosphate & C-source & carbohydrate & 48 & 164 & 125 & 176 \\
\hline PM2A & $\mathrm{H}$ & 9 & dihydroxyacetone & C-source & alcohol & 158 & 178 & 156 & 176 \\
\hline PM1 & A & 8 & L-proline & C-source & amino acid & 74 & 149 & 136 & 172 \\
\hline PM1 & C & 3 & D,L-malic acid & C-source & carboxylic acid & 0 & 125 & 125 & 172 \\
\hline PM1 & $\mathrm{C}$ & 10 & maltose & C-source & carbohydrate & 30 & 124 & 123 & 172 \\
\hline PM2A & $\mathrm{G}$ & 6 & L-histidine & \begin{tabular}{|l|}
$\mathrm{C}$-source \\
\end{tabular} & amino acid & 116 & 159 & 151 & 169 \\
\hline PM1 & $E$ & 10 & maltotriose & \begin{tabular}{|l|}
$\mathrm{C}$-source \\
\end{tabular} & carbohydrate & 52 & 110 & 120 & 168 \\
\hline PM1 & $\mathrm{C}$ & 9 & a-D-glucose & C-source & carbohydrate & 21 & 127 & 134 & 167 \\
\hline PM2A & $\mathrm{G}$ & 5 & glycine & C-source & amino acid & 0 & 123 & 113 & 163 \\
\hline PM1 & $\mathrm{G}$ & 8 & $\mathrm{~N}$-acetyl-D-mannosamine & C-source & carbohydrate & 0 & 130 & 124 & 162 \\
\hline PM1 & B & 8 & D-xylose & C-source & carbohydrate & 90 & 124 & 107 & 159 \\
\hline PM1 & $\mathrm{F}$ & 5 & fumaric acid & C-source & carboxylic acid & 35 & 101 & 126 & 159 \\
\hline PM1 & $\mathrm{G}$ & 4 & L-threonine & C-source & amino acid & 14 & 111 & 90 & 155 \\
\hline PM1 & A & 6 & D-galactose & C-source & carbohydrate & 111 & 148 & 162 & 154 \\
\hline PM1 & $\mathrm{F}$ & 12 & inosine & C-source & carbohydrate & 62 & 165 & 155 & 154 \\
\hline PM2A & $E$ & 12 & 5-keto-D-gluconic acid & C-source & carboxylic acid & 134 & 153 & 137 & 153 \\
\hline PM1 & D & 10 & lactulose & C-source & carbohydrate & 2 & 109 & 137 & 149 \\
\hline PM1 & $\mathrm{E}$ & 8 & b-methyl-D-glucoside & C-source & carbohydrate & 16 & 110 & 112 & 148 \\
\hline PM1 & A & 2 & L-Arabinose & C-source & carbohydrate & 98 & 128 & 111 & 139 \\
\hline PM1 & B & 3 & glycerol & C-source & carbohydrate & 56 & 133 & 104 & 139 \\
\hline PM1 & B & 10 & formic acid & C-source & carboxylic acid & 0 & 107 & 98 & 139 \\
\hline PM2A & $\mathrm{D}$ & 7 & turanose & C-source & carbohydrate & 68 & 130 & 123 & 134 \\
\hline PM1 & B & 9 & L-lactic acid & C-source & carboxylic acid & 10 & 108 & 102 & 128 \\
\hline PM2A & $\mathrm{C}$ & 5 & maltitol & C-source & carbohydrate & 83 & 157 & 164 & 124 \\
\hline PM2A & $B$ & 5 & D-arabinose & C-source & carbohydrate & 109 & 112 & 101 & 119 \\
\hline PM2A & $\mathrm{B}$ & 9 & 2-deoxy-D-ribose & \begin{tabular}{|l|}
$\mathrm{C}$-source \\
\end{tabular} & carbohydrate & 101 & 119 & 115 & 119 \\
\hline PM2A & $E$ & 5 & D-glucosamine & \begin{tabular}{|l|}
$\mathrm{C}$-source \\
\end{tabular} & carbohydrate & 104 & 116 & 116 & 113 \\
\hline PM1 & $\mathrm{G}$ & 6 & L-alanyl-glycine & \begin{tabular}{|l|}
$\mathrm{C}$-source \\
\end{tabular} & amino acid & 13 & 134 & 68 & 98 \\
\hline PM1 & $\mathrm{H}$ & 6 & L-Iyxose & C-source & carbohydrate & 110 & 157 & 132 & 95 \\
\hline PM1 & $\mathrm{H}$ & 8 & pyruvic acid & C-source & carboxylic acid & 66 & 113 & 85 & 93 \\
\hline PM2A & A & 6 & dextrin & C-source & polymer & 63 & 86 & 85 & 89 \\
\hline PM2A & $\mathrm{C}$ & 12 & palatinose & C-source & carbohydrate & 56 & 59 & 56 & 74 \\
\hline PM2A & $\mathrm{F}$ & 9 & sorbic acid & C-source & carboxylic acid & 33 & 88 & 53 & 74 \\
\hline PM2A & B & 8 & arbutin & C-source & carbohydrate & 33 & 47 & 49 & 72 \\
\hline PM1 & $\mathrm{G}$ & 7 & acetoacetic acid & C-source & carboxylic acid & 0 & 40 & 18 & 69 \\
\hline PM1 & $\mathrm{F}$ & 1 & glycyl-L-aspartic acid & C-source & amino acid & 0 & 6 & 0 & 59 \\
\hline PM2A & $\mathrm{F}$ & 5 & oxalomalic acid & C-source & carboxylic acid & 43 & 52 & 39 & 58 \\
\hline PM1 & $\mathrm{F}$ & 2 & citric acid & C-source & carboxylic acid & 0 & 0 & 30 & 57 \\
\hline PM1 & $\mathrm{H}$ & 1 & glycyl-L-proline & C-source & amino acid & 56 & 130 & 83 & 56 \\
\hline PM1 & G & 5 & L-alanine & C-source & amino acid & 0 & 40 & 0 & 54 \\
\hline
\end{tabular}

Biolog data analysis (Biolog projects L14 and L15) after background subtraction:

\begin{tabular}{|l|l|}
\hline Biolog end point reading & Inte rpretation \\
\hline $0-49$ & no growth \\
\hline $50-122$ & reduced growth \\
\hline $123-154$ & growth \\
\hline$>155$ & full growth \\
\hline
\end{tabular}

$>155$

full growth

Note: traffic light data analysis does not take into account the respiration curve shape, only end point (at 47 hour) Note: single Biolog plates run ( $\mathrm{n}=1$ )

Note: above tresholds for traffic light analysis validated via visual inspection of PM1 plate's respiration curves when background was not subtracted additionally highlighted from visual inspection of respiration curves when background was not subtracted 
Supplementary Data - Resistance. Assessment of S. aureus resistance to MGB-BP-3 following serial passaging in LB containing either MGB-BP-3 (3 independent populations at up to $0.5 x$ MIC80), rifampicin (one population at up to $0.4 x$ MIC80), or no antibiotic (control) for 80 generations. Cultures at corresponding OD600 were spotted on agar plates containing either rifampicin or MGB-BP-3 at $2 x$ MIC80 concentrations.

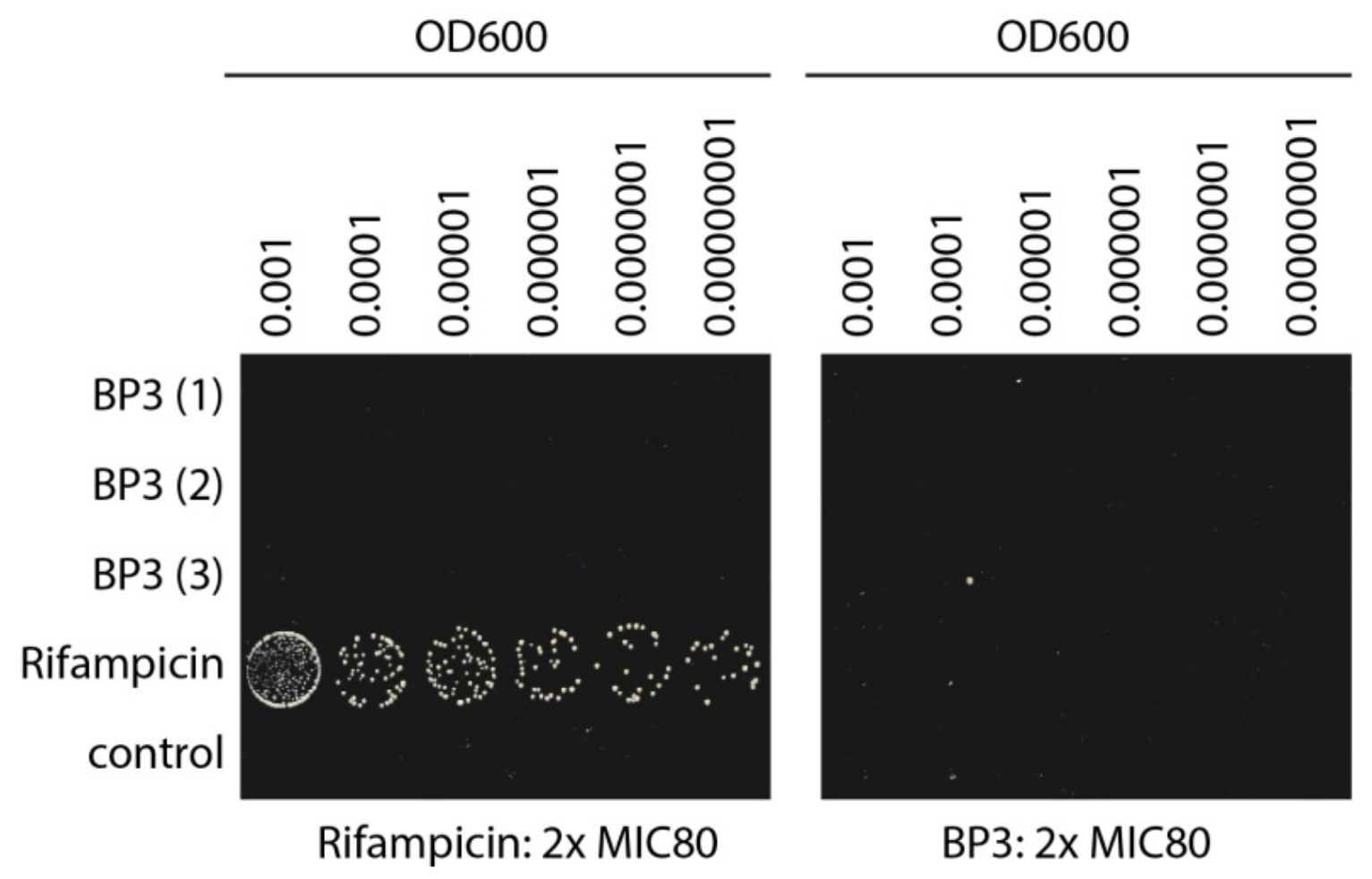


Supplementary Table 1: Primers used in qRT-PCR expression studies and Melt off analysis
Locus tag
Gene Name
Sequence (5'-3')

\section{qRT-PCR:}

SAOUHSC_00579 mvaK2 Saur_00579f TTAATCAAAAACTGGCCTGGAT

SAOUHSC_00579 mvaK2 Saur_00579r TTCGCTAACAAAGTGTGGTGAT

SAOUHSC_00795 gapA Saur_00795f GGCAGAAAACATCATCCCTAAC

SAOUHSC_00795 gapA Saur_00795r TGAAGCATTTTTCATAGCTTCG

SAOUHSC_00898 $\operatorname{argH} \quad$ Saur_00898f $\quad$ CTGGCTCATCTATTATGCCACA

SAOUHSC_00898 $\quad$ argH $\quad$ Saur_00898r $\quad$ GGACAGCATCGAATAAACCTTC

SAOUHSC_01171 pyrF $\quad$ Saur_01171f $\quad$ TTAGATGGCGTTGTTTGTTCAC

SAOUHSC_01171 pyrF Saur_01171r $\quad$ GGTCATTTTGAGATGCACCTTT

SAOUHSC_01490 hup Saur_01490f TTGCAGAGCAAGCTGATTTAAC

SAOUHSC_01490 hup Saur_01490r ACCTCAAAGTTACCGAAACCAA

SAOUHSC_01670 cold Saur_01670f CGTAGATGCAGATAAACCGTCA

SAOUHSC_01670 cdd Saur_01670r CTGCGACTGTCATCATAACCAT

SAOUHSC_01801 citC $\quad$ Saur_01801f $\quad$ ACTTGGCAACAATATGACCAAA

SAOUHSC_01801 citC Saur_01801r GCTCAGCTGGACGAGTTAAAAT 


\section{Melt off analysis:}

\begin{tabular}{llll}
\hline SAOUHSC_00006 & gyrA & SAOUHSC_00 & AGAGCCGTCAGTCTTACCTG \\
& & $006 \mathrm{for}$ & \\
& & & \\
\hline SAOUHSC_00006 & gyrA & SAOUHSC_00 & ACCTACCGCGATACCTGATG \\
& & $006 \mathrm{rev}$ & \\
& & & \\
\hline SAOUHSC_01146 & mraY & SAOUHSC_01 & ATTTGAAAAATTGATAATATATTA \\
& & 146for & GTG \\
& & & \\
\hline SAOUHSC_01146 & mraY & SAOUHSC_01 & CGCATATACAAAAATCATAACTAT \\
& & 146rev & CT \\
& & & \\
\hline SAOUHSC_01470 & dnaD & SAOUHSC_01 & AGCATTTTAGTCGAAAATTAAAGA \\
& & $470 f o r$ & A \\
& & & \\
\hline SAOUHSC_01470 & dnaD & SAOUHSC_01 & GATATTTATCCATGTTCGTGC \\
& & 470 rev &
\end{tabular}


Supplementary Table 2. List of genes differentially expressed by a factor of $\geq 2$ or $\leq-2$ in MGB-BP-3 treated S. aureus NCTC8325 compared to non-treated controls after $10 \mathrm{~min}$ of exposure.

\begin{tabular}{|c|c|c|}
\hline Locus tag & Gene $\quad$ Product & $\begin{array}{l}\text { Fold } \\
\text { change }\end{array}$ \\
\hline
\end{tabular}

\section{Downregulated}

Amino acid biosynthesis

\begin{tabular}{|c|c|c|}
\hline $\begin{array}{l}\text { SAOUHSC_00413 } \\
\text { SAOUHSC_01055 } \\
\text { SAOUHSC_01597 } \\
\text { SAOUHSC_01617 } \\
\text { SAOUHSC_01998 }\end{array}$ & $\begin{array}{l}\text { mpsB } \\
\operatorname{proC} \\
\arg R\end{array}$ & $\begin{array}{l}\text { hypothetical protein } \\
\text { inositol monophosphatase family protein } \\
\text { pyrroline-5-carboxylate reductase } \\
\text { arginine repressor } \\
\text { hypothetical protein }\end{array}$ \\
\hline
\end{tabular}

Biosynthesis of cofactors, prosthetic groups, and carriers

\begin{tabular}{|c|c|c|c|}
\hline SAOUHSC_00225 & $i s p D$ & $\begin{array}{l}\text { 2-C-methyl-D-erythritol 4-phosphate } \\
\text { cytidylyltransferase }\end{array}$ & -2 \\
\hline SAOUHSC_00723 & $p a b B$ & hypothetical protein & -4 \\
\hline SAOUHSC_00724 & & chorismate binding protein & -5 \\
\hline SAOUHSC_00847 & sufC & ABC transporter ATP-binding protein & -3 \\
\hline SAOUHSC_00848 & sufD & hypothetical protein & -2 \\
\hline SAOUHSC_00980 & menA & $\begin{array}{l}\text { 1,4-dihydroxy-2-naphthoate } \\
\text { octaprenyltransferase }\end{array}$ & -4 \\
\hline SAOUHSC_01178 & $\mathrm{coaBC}$ & $\begin{array}{l}\text { bifunctional } \\
\text { phosphopantothenoylcysteine } \\
\text { decarboxylase/phosphopantothenate-- } \\
\text { cysteine ligase }\end{array}$ & -4 \\
\hline SAOUHSC_01190 & thiN & hypothetical protein & -4 \\
\hline SAOUHSC_01356 & glct & transcription antiterminator & -8 \\
\hline SAOUHSC_01486 & hepT & $\begin{array}{l}\text { heptaprenyl diphosphate syntase } \\
\text { component II }\end{array}$ & -4 \\
\hline SAOUHSC_01487 & $u b i E$ & $\begin{array}{l}\text { ubiquinone/menaquinone biosynthesis } \\
\text { methyltransferase }\end{array}$ & -3 \\
\hline SAOUHSC 01776 & hemA & glutamyl-tRNA reductase & -4 \\
\hline SAOUHSC_01795 & coaE & dephospho-CoA kinase & -2 \\
\hline SAOUHSC_01882 & & hypothetical protein & -4 \\
\hline SAOUHSC_01915 & menc & hypothetical protein & -3 \\
\hline SAOUHSC_01916 & menE & 2-succinylbenzoate-CoA ligase & -6 \\
\hline SAOUHSC_02132 & nadE & NAD synthetase & -3 \\
\hline SAOUHSC_02133 & & nicotinate phosphoribosyltransferase & -3 \\
\hline \multicolumn{4}{|l|}{ Cell envelope } \\
\hline SAOUHSC_OC & & hypothetical protein & -5 \\
\hline
\end{tabular}




\begin{tabular}{|c|c|c|}
\hline SAOUHSC_00471 & $g \operatorname{lmU}$ & $\begin{array}{l}\text { bifunctional } \mathrm{N} \text {-acetylglucosamine-1- } \\
\text { phosphate } \\
\text { uridyltransferase/glucosamine-1- } \\
\text { phosphate acetyltransferase }\end{array}$ \\
\hline SAOUHSC_00535 & & hypothetical protein \\
\hline SAOUHSC_00640 & $\operatorname{tag} A$ & teichoic acid biosynthesis protein \\
\hline SAOUHSC_00643 & $\operatorname{tag} B$ & teichoic acid biosynthesis protein TagB \\
\hline SAOUHSC_00752 & murB & $\begin{array}{l}\text { UDP-N-acetylenolpyruvoylglucosamine } \\
\text { reductase }\end{array}$ \\
\hline SAOUHSC_00953 & ugtP & diacylglycerol glucosyltransferase \\
\hline SAOUHSC_01051 & & hypothetical protein \\
\hline SAOUHSC_01063 & & hypothetical protein \\
\hline SAOUHSC_01145 & $p b p 1$ & penicillin-binding protein 1 \\
\hline SAOUHSC_01146 & $\operatorname{mraY}$ & $\begin{array}{l}\text { phospho-N-acetylmuramoyl- } \\
\text { pentapeptide- transferase }\end{array}$ \\
\hline SAOUHSC_01147 & murD & $\begin{array}{l}\text { UDP-N-acetylmuramoyl-L-alanyl-D- } \\
\text { glutamate synthetase }\end{array}$ \\
\hline SAOUHSC_01758 & $m r e D$ & hypothetical protein \\
\hline SAOUHSC_01759 & mreC & rod shape-determining protein MreC \\
\hline SAOUHSC_01812 & & hypothetical protein \\
\hline SAOUHSC_02305 & alr & alanine racemase \\
\hline SAOUHSC_02319 & & hypothetical protein \\
\hline
\end{tabular}

Cellular processes

\begin{tabular}{|c|c|c|}
\hline SAOUHSC_00024 & walJ & hypothetical protein \\
\hline SAOUHSC_00185 & hptS & hypothetical protein \\
\hline SAOUHSC_00299 & & hypothetical protein \\
\hline SAOUHSC_00479 & & hypothetical protein \\
\hline SAOUHSC_00685 & & hypothetical protein \\
\hline SAOUHSC_00789 & whiA & hypothetical protein \\
\hline SAOUHSC_00819 & $\operatorname{cspC}$ & hypothetical protein \\
\hline SAOUHSC_00948 & & hypothetical protein \\
\hline SAOUHSC_01039 & & hypothetical protein \\
\hline SAOUHSC_01063 & & hypothetical protein \\
\hline SAOUHSC_01142 & $m r a Z$ & cell division protein MraZ \\
\hline SAOUHSC_01144 & $f t s L$ & cell division protein \\
\hline SAOUHSC_01145 & $p b p 1$ & penicillin-binding protein 1 \\
\hline SAOUHSC_01213 & & hypothetical protein \\
\hline SAOUHSC_01317 & & hypothetical protein \\
\hline SAOUHSC_01382 & & hypothetical protein \\
\hline SAOUHSC_01407 & & hypothetical protein \\
\hline SAOUHSC_01431 & $m s r B$ & methionine sulfoxide reductase $B$ \\
\hline SAOUHSC_01432 & msrA1 & methionine sulfoxide reductase $A$ \\
\hline SAOUHSC_01827 & $e z r A$ & septation ring formation regulator EzrA \\
\hline SAOUHSC_01871 & & polysaccharide biosynthesis protein \\
\hline SAOUHSC_01999 & & hypothetical protein \\
\hline SAOUHSC_02098 & $\operatorname{vraR}$ & DNA-binding response regulator VraR \\
\hline SAOUHSC_02121 & & hypothetical protein \\
\hline SAOUHSC_02319 & & hypothetical protein \\
\hline SAOUHSC_02591 & & hypothetical protein \\
\hline
\end{tabular}


SAOUHSC_02811 reIP hypothetical protein -2

\section{Central intermediary metabolism}

\begin{tabular}{|c|c|c|}
\hline SAOUHSC_00471 & $g / m U$ & $\begin{array}{l}\text { bifunctional } \mathrm{N} \text {-acetylglucosamine-1- } \\
\text { phosphate } \\
\text { uridyltransferase/glucosamine-1- } \\
\text { phosphate acetyltransferase }\end{array}$ \\
\hline $\begin{array}{l}\text { SAOUHSC_00552 } \\
\text { SAOUHSC_01650 } \\
\text { SAOUHSC_01987 }\end{array}$ & $\operatorname{nag} B$ & $\begin{array}{l}\text { hypothetical protein } \\
\text { 5-formyltetrahydrofolate cyclo-ligase } \\
\text { hypothetical protein }\end{array}$ \\
\hline SAOUHSC_02011 & recX & recombination regulator $\operatorname{Rec} X$ \\
\hline SAOUHSC_02142 & aldH & aldehyde dehydrogenase \\
\hline SAOUHSC_02259 & & hypothetical protein \\
\hline SAOUHSC_02793 & & hypothetical protein \\
\hline
\end{tabular}

DNA metabolism

\begin{tabular}{|c|c|c|}
\hline SAOUHSC_00162 & $h s d R$ & $\begin{array}{l}\text { HsdR family type I site-specific } \\
\text { deoxyribonuclease }\end{array}$ \\
\hline SAOUHSC_00477 & $m f d$ & transcription-repair coupling factor \\
\hline SAOUHSC_00819 & $\operatorname{csp} C$ & hypothetical protein \\
\hline SAOUHSC_01039 & & hypothetical protein \\
\hline SAOUHSC_01179 & priA & primosomal protein $\mathrm{N}$ \\
\hline SAOUHSC_01333 & $\operatorname{lex} A$ & LexA repressor \\
\hline SAOUHSC_01336 & & hypothetical protein \\
\hline SAOUHSC_01454 & & hypothetical protein \\
\hline SAOUHSC_01469 & nth & endonuclease III \\
\hline SAOUHSC_01470 & $d n a D$ & hypothetical protein \\
\hline SAOUHSC_01472 & $\operatorname{din} G$ & $\begin{array}{l}\text { DnaQ family exonuclease/DinG family } \\
\text { helicase }\end{array}$ \\
\hline SAOUHSC_01615 & recN & DNA repair protein $\mathrm{RecN}$ \\
\hline SAOUHSC_01667 & $\mathrm{recO}$ & hypothetical protein \\
\hline SAOUHSC_01673 & phoH & hypothetical protein \\
\hline SAOUHSC_01796 & mutM & formamidopyrimidine-DNA glycosylase \\
\hline SAOUHSC_01797 & polA & DNA polymerase I \\
\hline SAOUHSC_01811 & dnaE & $\begin{array}{l}\text { DNA polymerase III subunit alpha } \\
\text { superfamily protein }\end{array}$ \\
\hline SAOUHSC_01827 & $e z r A$ & septation ring formation regulator EzrA \\
\hline
\end{tabular}

Energy metabolism

SAOUHSC 00100

SAOUHSC 00226

SAOUHSC 00412

SAOUHSC_00616

SAOUHSC_00756

SAOUHSC_01189

SAOUHSC 01599

SAOUHSC 01665

SAOUHSC 01801

SAOUHSC_01867

SAOUHSC 01901

$\begin{array}{lll}\text { deoC1 } & \text { 2-deoxyribose-5-phosphate aldolase } & -4 \\ \text { tarJ } & \text { hypothetical protein } & -3 \\ \text { mpsA } & \text { NADH dehydrogenase subunit 5 } & -6 \\ & \text { hypothetical protein } & -3 \\ & \text { hypothetical protein } & -3 \\ \text { cfxE } & \text { ribulose-phosphate 3-epimerase } & -5 \\ \text { zwf } & \text { glucose-6-phosphate 1-dehydrogenase } & -4 \\ & \text { CBS domain-containing protein } & -3 \\ \text { citC } & \text { isocitrate dehydrogenase } & -3 \\ \text { dat } & \text { D-alanine aminotransferase } & -4 \\ \text { tal } & \text { putative translaldolase }\end{array}$

$-3$ 
SAOUHSC 01912

SAOUHSC_02550 fdhD

SAOUHSC_02808

SAOUHSC_02845 hypothetical protein

$-4$

formate dehydrogenase accessory $\quad-3$

protein

gntK gluconate kinase

$-3$

hypothetical protein
$-6$

Fatty acid and phospholipid metabolism

SAOUHSC_01350 plsY hypothetical protein

SAOUHSC_02306 acpS 4'-phosphopantetheinyl transferase $\quad-3$

Mobile and extrachromosomal element functions

\begin{tabular}{llll}
\hline SAOUHSC_01374 & femB & methicillin resistance factor & -3 \\
SAOUHSC_01464 & & hypothetical protein & -4 \\
SAOUHSC_01470 & dnaD & hypothetical protein & -5
\end{tabular}

\section{Protein fate}

SAOUHSC_00547

SAOUHSC_00639

SAOUHSC_00963

SAOUHSC_00973

SAOUHSC 01038

SAOUHSC_01182

SAOUHSC_01406

SAOUHSC_01431

SAOUHSC_01432

SAOUHSC_01626

SAOUHSC 01629

SAOUHSC 01838

SAOUHSC_02013

SAOUHSC 02102

SAOUHSC_02472

SAOUHSC_02984 hypothetical protein

hypothetical protein

$-3$

IpIA1

ligase

tarM hypothetical protein $\quad-4$

def peptide deformylase -3

def2 peptide deformylase -3

acy $P$ acylphosphatase

$m s r B$ methionine sulfoxide reductase $B \quad-3$

msrA1 methionine sulfoxide reductase A

pepQ2 proline dipeptidase -2

lipM hypothetical protein -4

htrA1 hypothetical protein -4

hypothetical protein -3

map methionine aminopeptidase $\quad-6$

hypothetical protein -4

accessory Sec system -3

glycosyltransferase GtfA

Protein synthesis

SAOUHSC 00475

SAOUHSC 00605

SAOUHSC 00663

SAOUHSC 00933

SAOUHSC_00979

SAOUHSC_01091

SAOUHSC_01143

pth

peptidyl-tRNA hydrolase

hypothetical protein

hypothetical protein

trps

tryptophanyl-tRNA synthetase

$-2$

hypothetical protein

hypothetical protein

mraW

16S rRNA (cytosine(1402)-N(4))-

$-2$

methyltransferase

SAOUHSC_01183

SAOUHSC_01188

SAOUHSC_01214

SAOUHSC_01455

fmt

methionyl-tRNA formyltransferase

$-9$

$\operatorname{rsg} A$

hypothetical protein

$-2$

$\operatorname{rbg} A$

ribosomal biogenesis GTPase

hypothetical protein

$-6$

SAOUHSC_01668

era

SAOUHSC_01672

ybeY

GTP-binding protein Era

$-3$

$-5$

$-4$

$-5$ 


\begin{tabular}{llll} 
SAOUHSC_01865 & trmB & tRNA (guanine-N(7)-)-methyltransferase & -3 \\
SAOUHSC_01870 & & 16S rRNA pseudouridine(516) synthase & -3 \\
SAOUHSC_02297 & & S1 RNA-binding domain-containing & -2 \\
& & protein & \\
SAOUHSC_02480 & \multirow{2}{*}{ truA } & tRNA pseudouridine synthase A & -2 \\
SAOUHSC_02519 & & hypothetical protein & -3 \\
SAOUHSC_02651 & & hypothetical protein & -3
\end{tabular}

Purines, pyrimidines, nucleosides, and nucleotides

\begin{tabular}{lllr}
\hline SAOUHSC_00100 & deoC1 & 2-deoxyribose-5-phosphate aldolase & -4 \\
SAOUHSC_00101 & deoB & $\begin{array}{l}\text { phosphopentomutase } \\
\text { ribonucleotide reductase stimulatory } \\
\text { protein } \\
\text { SAOUHSC_00741 }\end{array}$ & -3 \\
nrdbonucleotide-diphosphate reductase & -4 \\
SAOUHSC_00743 & nrdF & -4 \\
SAbunit beta & -3 \\
SAOUHSC_01435 & thyA & $\begin{array}{l}\text { thymidylate synthase } \\
\text { cytidine deaminase }\end{array}$ & -4
\end{tabular}

Regulatory functions

\begin{tabular}{|c|c|c|}
\hline SAOUHSC_00020 & walR & two-component response regulator \\
\hline SAOUHSC_00070 & sars & accessory regulator-like protein \\
\hline SAOUHSC_00231 & lytR & two-component response regulator \\
\hline SAOUHSC_00242 & rbsR & hypothetical protein \\
\hline SAOUHSC_00665 & graR & hypothetical protein \\
\hline SAOUHSC_00674 & $\operatorname{sar} X$ & hypothetical protein \\
\hline SAOUHSC_00675 & & hypothetical protein \\
\hline SAOUHSC_00679 & $\operatorname{ccp} E$ & hypothetical protein \\
\hline SAOUHSC_00685 & & hypothetical protein \\
\hline SAOUHSC_01142 & mraZ & cell division protein MraZ \\
\hline SAOUHSC_01285 & $g \ln R$ & glutamine synthetase repressor \\
\hline SAOUHSC_01333 & lexA & LexA repressor \\
\hline SAOUHSC_01361 & $m s r R$ & transcriptional regulator \\
\hline SAOUHSC_01464 & & hypothetical protein \\
\hline SAOUHSC_01586 & srrA & DNA-binding response regulator \\
\hline SAOUHSC_01617 & $\arg R$ & arginine repressor \\
\hline SAOUHSC_01685 & hrcA & $\begin{array}{l}\text { heat-inducible transcription repressor } \\
\mathrm{HrcA}\end{array}$ \\
\hline SAOUHSC_01793 & $n r d R$ & transcriptional regulator NrdR \\
\hline SAOUHSC_01800 & phoP & $\begin{array}{l}\text { alkaline phosphatase synthesis } \\
\text { transcriptional regulatory protein }\end{array}$ \\
\hline SAOUHSC_02014 & & hypothetical protein \\
\hline SAOUHSC_02300 & $r s b V$ & STAS domain-containing protein \\
\hline SAOUHSC_02456 & lach & $\begin{array}{l}\text { lactose phosphotransferase system } \\
\text { repressor }\end{array}$ \\
\hline SAOUHSC_0258: & & transcriptional regulator \\
\hline SAOUHSC_02635 & tcaA & hypothetical protein \\
\hline SAOUHSC_02956 & $n s a R$ & $\begin{array}{l}\text { nisin susceptibility-associated DNA- } \\
\text { binding response regulator }\end{array}$ \\
\hline
\end{tabular}




\begin{tabular}{|c|c|c|c|}
\hline SAOUHSC_00020 & walR & two-component response regulator & -4 \\
\hline SAOUHSC_00021 & walk & sensory box histidine kinase VicK & -4 \\
\hline SAOUHSC_00230 & lytS & two-component sensor histidine kinase & -4 \\
\hline SAOUHSC_00313 & & hypothetical protein & -2 \\
\hline SAOUHSC_00665 & graR & hypothetical protein & -3 \\
\hline SAOUHSC_00666 & gras & hypothetical protein & -4 \\
\hline SAOUHSC_01586 & srrA & DNA-binding response regulator & -3 \\
\hline SAOUHSC_01799 & phoR & histidine kinase & -4 \\
\hline SAOUHSC_01800 & phoP & $\begin{array}{l}\text { alkaline phosphatase synthesis } \\
\text { transcriptional regulatory protein }\end{array}$ & -5 \\
\hline SAOUHSC_02400 & $m t / F$ & PTS system mannitol-specific protein & -6 \\
\hline SAOUHSC_02955 & nsaS & $\begin{array}{l}\text { nisin susceptibility-associated sensor } \\
\text { histidine kinase }\end{array}$ & -2 \\
\hline SAOUHSC_02956 & nsaR & $\begin{array}{l}\text { nisin susceptibility-associated DNA- } \\
\text { binding response regulator }\end{array}$ & -3 \\
\hline SAOUHSC_02974 & & hypothetical protein & -3 \\
\hline \multicolumn{4}{|l|}{ Transcription } \\
\hline SAOUHSC_01035 & rnjA & hypothetical protein & -3 \\
\hline SAOUHSC_01252 & $r n j B$ & hypothetical protein & -3 \\
\hline \multicolumn{4}{|c|}{ Transport and binding proteins } \\
\hline SAOUHSC_00060 & & hypothetical protein & -3 \\
\hline SAOUHSC_00067 & $\operatorname{lctP1}$ & L-lactate permease & -3 \\
\hline SAOUHSC_00114 & capA & $\begin{array}{l}\text { capsular polysaccharide biosynthesis } \\
\text { protein }\end{array}$ & -5 \\
\hline SAOUHSC_00151 & brnQ1 & $\begin{array}{l}\text { branched-chain amino acid transport } \\
\text { system II carrier protein }\end{array}$ & -5 \\
\hline SAOUHSC_00175 & malk & $\begin{array}{l}\text { multiple sugar-binding transport ATP- } \\
\text { binding protein }\end{array}$ & -5 \\
\hline SAOUHSC_00186 & hptA & lipoprotein & -3 \\
\hline SAOUHSC_00313 & & hypothetical protein & -2 \\
\hline SAOUHSC_00556 & proP & proline/betaine transporter & -3 \\
\hline SAOUHSC_00633 & & hypothetical protein & -3 \\
\hline SAOUHSC_00641 & $\operatorname{tag} H$ & $\begin{array}{l}\text { teichoic acids export protein ATP-binding } \\
\text { subunit }\end{array}$ & -2 \\
\hline SAOUHSC_00681 & & $\begin{array}{l}\text { major facilitator superfamily protein } \\
\text { superfamily }\end{array}$ & -3 \\
\hline SAOUHSC_00731 & ориBA & $\mathrm{ABC}$ transporter & -4 \\
\hline SAOUHSC_00740 & & hypothetical protein & -8 \\
\hline SAOUHSC_00787 & & hypothetical protein & -5 \\
\hline SAOUHSC_00885 & mnhE & $\begin{array}{l}\text { monovalent cation/H+ antiporter subunit } \\
\text { E }\end{array}$ & -3 \\
\hline SAOUHSC_00886 & $m n h D$ & $\begin{array}{l}\text { monovalent cation/H+ antiporter subunit } \\
\text { D }\end{array}$ & -3 \\
\hline SAOUHSC_00887 & $m n h C$ & $\begin{array}{l}\text { monovalent cation/H+ antiporter subunit } \\
\mathrm{C}\end{array}$ & -3 \\
\hline SAOUHSC_00888 & $m n h B$ & $\begin{array}{l}\text { monovalent cation/H+ antiporter subunit } \\
\text { B }\end{array}$ & -4 \\
\hline
\end{tabular}




\begin{tabular}{|c|c|c|}
\hline SAOUHSC_00889 & $m n h A$ & $\begin{array}{l}\text { monovalent cation } / \mathrm{H}+\text { antiporter subunit } \\
\text { A }\end{array}$ \\
\hline SAOUHSC_00923 & $\begin{array}{l}\text { opp- } \\
3 B\end{array}$ & hypothetical protein \\
\hline SAOUHSC_00924 & $\begin{array}{l}\text { opp- } \\
3 C\end{array}$ & hypothetical protein \\
\hline SAOUHSC_00925 & $\begin{array}{l}\text { opp- } \\
3 D\end{array}$ & hypothetical protein \\
\hline SAOUHSC_01326 & & hypothetical protein \\
\hline SAOUHSC_01505 & & hypothetical protein \\
\hline SAOUHSC_01803 & аaрA & hypothetical protein \\
\hline SAOUHSC_01967 & & $\mathrm{ABC}$ transporter ATP-binding protein \\
\hline SAOUHSC_02006 & & hypothetical protein \\
\hline SAOUHSC_02009 & & hypothetical protein \\
\hline SAOUHSC_02247 & & cation transport protein \\
\hline SAOUHSC_02400 & $m t / F$ & PTS system mannitol-specific protein \\
\hline SAOUHSC_02482 & cbiO_1 & cobalt transporter ATP-binding subunit \\
\hline SAOUHSC_02483 & cbiO_2 & cobalt transporter ATP-binding subunit \\
\hline SAOUHSC_02597 & $g / v C$ & PTS system transporter \\
\hline SAOUHSC_02601 & & $\mathrm{Na}+/ \mathrm{H}+$ antiporter \\
\hline SAOUHSC_02729 & & amino acid $A B C$ transporter-like protein \\
\hline SAOUHSC_02797 & & hypothetical protein \\
\hline SAOUHSC_02806 & gntP & gluconate permease \\
\hline SAOUHSC_02815 & & hypothetical protein \\
\hline SAOUHSC_0297 & & hypothetical protein \\
\hline
\end{tabular}

Unknown TIGRFAM main role

\begin{tabular}{|c|c|c|c|}
\hline SAOUHSC_00014 & & hypothetical protein & -3 \\
\hline SAOUHSC_00022 & wall & hypothetical protein & -3 \\
\hline SAOUHSC_00023 & wall & hypothetical protein & -2 \\
\hline SAOUHSC_00056 & & hypothetical protein & 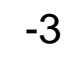 \\
\hline SAOUHSC_00125 & capl & cap5L protein/glycosyltransferase & -4 \\
\hline SAOUHSC_00130 & isdl & heme-degrading monooxygenase Isdl & -3 \\
\hline SAOUHSC_00163 & & hypothetical protein & -5 \\
\hline SAOUHSC_00164 & & hypothetical protein & -5 \\
\hline SAOUHSC_00166 & & hypothetical protein & - \\
\hline SAOUHSC_00176 & male & extracellular solute-binding protein & -4 \\
\hline SAOUHSC_00178 & & maltose $\mathrm{ABC}$ transporter permease & -3 \\
\hline SAOUHSC_00227 & $\operatorname{tarL}$ & hypothetical protein & -2 \\
\hline SAOUHSC_00232 & $\operatorname{Irg} A$ & murein hydrolase regulator LrgA & -5 \\
\hline SAOUHSC_00256 & & hypothetical protein & $-i$ \\
\hline SAOUHSC_00322 & & hypothetical protein & -3 \\
\hline SAOUHSC_00324 & & $\begin{array}{l}50 \text { S ribosomal protein } \mathrm{L} 7 \text { serine } \\
\text { acetyltransferase }\end{array}$ & 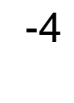 \\
\hline SAOUHSC_00342 & & $\begin{array}{l}\text { ParB family chromosome partioning } \\
\text { protein }\end{array}$ & $-c$ \\
\hline C_00370 & & hypothetical protein & -3 \\
\hline SAOUHSC_00382 & & hypothetical protein & -4 \\
\hline SAOUHSC_00450 & & Orn/Lys/Arg decarboxylase & - \\
\hline SAOUHSC_00585 & & hypothetical protein & \\
\hline
\end{tabular}


SAOUHSC_00586

SAOUHSC_00587

SAOUHSC_00588

SAOUHSC_00593

SAOUHSC_00613

SAOUHSC_00614

SAOUHSC_00615

SAOUHSC_00664

SAOUHSC 00673

SAOUHSC 00678

SAOUHSC_00682

SAOUHSC_00683

SAOUHSC_00686

SAOUHSC_00687

SAOUHSC_00692

SAOUHSC_00693

SAOUHSC_00712

SAOUHSC_00722

SAOUHSC 00726

SAOUHSC_00727

SAOUHSC 00732

SAOUHSC_00736

SAOUHSC 00742

SAOUHSC 00751

SAOUHSC_00774

SAOUHSC_00783

SAOUHSC_00784

SAOUHSC 00788

SAOUHSC 00800

SAOUHSC 00824

SAOUHSC 00830

SAOUHSC 00854

SAOUHSC_00855

SAOUHSC 00860

SAOUHSC_00864

SAOUHSC_00865

SAOUHSC_00875

SAOUHSC 00890

SAOUHSC 00906

SAOUHSC_00938

SAOUHSC 00939

SAOUHSC 00940

SAOUHSC 00952

SAOUHSC 00962

SAOUHSC_00974

SAOUHSC_01025

SAOUHSC_01036 hypothetical protein $\quad-6$

hypothetical protein $\quad-6$

hypothetical protein $\quad-6$

unknown $\quad-78$

iron compound $\mathrm{ABC}$ transporter $\quad-3$

substrate-binding protein

hypothetical protein -3

haloacid dehalogenase-like hydrolase $\quad-4$

hypothetical protein -3

hypothetical protein -5

hypothetical protein $\quad-6$

hypothetical protein -3

hypothetical protein $\quad-6$

hypothetical protein $\quad-5$

hypothetical protein $\quad-4$

hypothetical protein -3

hypothetical protein -3

hypothetical protein -3

pabA para-aminobenzoate synthase glutamine $\quad-6$

amidotransferase component II

hypothetical protein -4

hypothetical protein -3

opuBB amino acid ABC transporter permease $\quad-2$

hypothetical protein -3

$n r d E$ ribonucleotide-diphosphate reductase -3

subunit alpha

hypothetical protein -3

hypothetical protein -3

hypothetical protein -3

hypothetical protein -3

hypothetical protein $\quad-4$

hypothetical protein $\quad-5$

hypothetical protein $\quad-11$

hypothetical protein $\quad-4$

hypothetical protein -5

hypothetical protein -5

5-nucleotidase family protein $\quad-2$

hypothetical protein -3

hypothetical protein -3

hypothetical protein $\quad-4$

kapB hypothetical protein -5

hypothetical protein -3

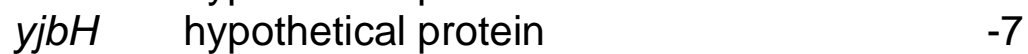

hypothetical protein $\quad-6$

hypothetical protein -3

hypothetical protein $\quad-4$

hypothetical protein $\quad-4$

hypothetical protein -5

hypothetical protein $\quad-6$

rpoY hypothetical protein -3

$-78$

$-4$

$-3$

$-3$

$-3$


SAOUHSC_01050

SAOUHSC_01082

SAOUHSC_01119

SAOUHSC_01120

SAOUHSC_01152

SAOUHSC_01265

SAOUHSC_01266

SAOUHSC_01267

SAOUHSC 01354

SAOUHSC_01359

SAOUHSC_01391

SAOUHSC_01405

SAOUHSC_01408

SAOUHSC_01414

SAOUHSC_01419

SAOUHSC_01429

SAOUHSC_01433

SAOUHSC_01434

SAOUHSC 01463

SAOUHSC 01474

SAOUHSC_01488

SAOUHSC_01584

SAOUHSC_01596

SAOUHSC_01600

SAOUHSC_01606

SAOUHSC 01614

SAOUHSC_01627

SAOUHSC_01645

SAOUHSC_01646

SAOUHSC 01648

SAOUHSC 01664

SAOUHSC 01671

SAOUHSC 01684

SAOUHSC_01706

SAOUHSC 01798

SAOUHSC_01802

SAOUHSC_01847

SAOUHSC_01849

SAOUHSC 01868

SAOUHSC 01895

SAOUHSC 01896

SAOUHSC_01908

SAOUHSC 01914

SAOUHSC_01957

SAOUHSC_01958

SAOUHSC_01966

SAOUHSC_01986

SAOUHSC 01997

SAOUHSC_02004 hypothetical protein -3

isdC hypothetical protein -3

hypothetical protein -3

hypothetical protein -2

hypothetical protein -3

hypothetical protein $\quad-6$

hypothetical protein -5

2-oxoglutarate ferredoxin oxidoreductase -3 subunit beta

alsT sodium:alanine symporter family protein -2

$f m t C$ hypothetical protein -3

CVfB hypothetical protein -2

hypothetical protein -5

hypothetical protein $\quad-4$

hypothetical protein -2

arls hypothetical protein -3

hypothetical protein -2

fakB2 hypothetical protein -3

dfrA dihydrofolate reductase -3

hypothetical protein -3

papS tRNA CCA-pyrophosphorylase -3

hypothetical protein $\quad-4$

hypothetical protein $\quad-4$

hypothetical protein -5

hypothetical protein $\quad-4$

peptidase $T$

IpdA dihydrolipoamide dehydrogenase $\quad-2$

hypothetical protein -5

hypothetical protein $\quad-2$

glk glucokinase -2

hypothetical protein $\quad-2$

hypothetical protein -2

dgkA diacylglycerol kinase -5

grpe heat shock protein GrpE -3

hypothetical protein $\quad-8$

hypothetical protein $\quad-4$

citZ hypothetical protein $\quad-4$

acu $A$ hypothetical protein $\quad-4$

acuC acetoin utilization protein AcuC $\quad-4$

dipeptidase PepV $\quad-4$

hypothetical protein $\quad-4$

hypothetical protein $\quad-7$

hypothetical protein $\quad-4$

hypothetical protein -3

hypothetical protein -5

hypothetical protein -3

hypothetical protein -3

hypothetical protein -3

perR ferric uptake regulator-like protein $\quad-5$

hypothetical protein -3 
SAOUHSC 02007

SAOUHSC_02008

SAOUHSC 02010

SAOUHSC 02087

SAOUHSC_02093

SAOUHSC_02100

SAOUHSC_02101

SAOUHSC_02103

SAOUHSC 02111

SAOUHSC 02114

SAOUHSC 02131

SAOUHSC_02134

SAOUHSC-02135

SAOUHSC_02139

SAOUHSC_02146

SAOUHSC 02147

SAOUHSC_02148

SAOUHSC_02149

SAOUHSC_02256

SAOUHSC 02257

SAOUHSC_02273

SAOUHSC 02274

SAOUHSC 02298

SAOUHSC_02299

SAOUHSC 02301

SAOUHSC 02302

SAOUHSC_02303

SAOUHSC_02304

SAOUHSC 02307

SAOUHSC 02308

SAOUHSC 02309

SAOUHSC 02335

SAOUHSC 02367

SAOUHSC 02383

SAOUHSC_02390

SAOUHSC_02396

SAOUHSC_02428

SAOUHSC_02430

SAOUHSC 02448

SAOUHSC 02464

SAOUHSC 02465

SAOUHSC 02471

SAOUHSC 02473

SAOUHSC_02474

SAOUHSC 02556

SAOUHSC_02567

SAOUHSC_02574

SAOUHSC_02582 hypothetical protein

hypothetical protein

hypothetical protein

hypothetical protein

hypothetical protein

vraT hypothetical protein

vraU hypothetical protein

hypothetical protein

$\operatorname{din} P$

DNA polymerase IV

lipid kinase

$-8$

$-6$

$-3$

$-4$

$-4$

hypothetical protein

$-2$

nitric oxide synthase oxygenase subunit -3

pheA

hypothetical protein

pyrazinamidase/nicotinamidase $\quad-3$

hypothetical protein -3

hypothetical protein $\quad-6$

hypothetical protein $\quad-6$

hypothetical protein $\quad-7$

hypothetical protein $\quad-5$

$\mathrm{sdrH}$ hypothetical protein -6

rex redox-sensing transcriptional repressor -3

Rex

vga $\quad A B C$ transporter ATP-binding protein -3

sigB RNA polymerase sigma factor SigB $\quad-6$

rsbW serine-protein kinase RsbW

$r s b U$ putative sigmaB regulation protein -3

hypothetical protein -3

maz $F$ hypothetical protein -4

mazE hypothetical protein -3

hypothetical protein -3

hypothetical protein -6

hypothetical protein $\quad-9$

$\begin{array}{ll}y w p F & \text { hypothetical protein }\end{array}$

hypothetical protein $\quad-4$

hypothetical protein -3

lytic regulatory protein $\quad-7$

hypothetical protein -2

$h t s B$ hypothetical protein -3

$h t s A \quad A B C$ transporter substrate-binding $\quad-3$

protein

hypothetical protein $\quad-7$

hypothetical protein $\quad-4$

hypothetical protein $\quad-4$

hypothetical protein -5

hypothetical protein -8

hypothetical protein $\quad-5$

hypothetical protein $\quad-4$

hypothetical protein -3

hypothetical protein -3

$f d h A$ formate dehydrogenase subunit alpha -3 
SAOUHSC 02592

SAOUHSC_02611

SAOUHSC_02613

SAOUHSC_02631

SAOUHSC_02633

SAOUHSC_02638

SAOUHSC_02650

SAOUHSC_02663

SAOUHSC_02669

SAOUHSC 02686

SAOUHSC 02694

SAOUHSC 02725

SAOUHSC_02727

SAOUHSC_02736

SAOUHSC_02787

SAOUHSC_02789

SAOUHSC_02790

SAOUHSC_02816

SAOUHSC_02846

SAOUHSC 02880

SAOUHSC 02910

SAOUHSC_02929

SAOUHSC 02931

SAOUHSC 02947

SAOUHSC_02982

SAOUHSC_03001

SAOUHSC_03034

SAOUHSC_A01081

SAOUHSC A01723 hypothetical protein -5

lyrA hypothetical protein -3

hypothetical protein $\quad-2$

hypothetical protein $\quad-4$

hypothetical protein $\quad-4$

hypothetical protein -3

hypothetical protein $\quad-2$

hypothetical protein $\quad-4$

sarZ hypothetical protein -3

hypothetical protein -3

$d s b A \quad$ hypothetical protein $\quad-4$

hypothetical protein $\quad-4$

hypothetical protein $\quad-15$

hypothetical protein -3

hypothetical protein -3

hypothetical protein $\quad-6$

hypothetical protein -3

hypothetical protein $\quad-4$

hypothetical protein $\quad-10$

crtQ hypothetical protein -2

hypothetical protein -3

acetyl-CoA synthetase $\quad-5$

hypothetical protein -22

cysJ sulfite reductase (NADPH) flavoprotein -6

subunit alpha

sasF hypothetical protein -3

$i c a R$ ica operon transcriptional regulator IcaR $\quad-4$

hypothetical protein -3

hypothetical protein $\quad-4$

hypothetical protein $\quad-9$

\section{Upregulated}

Amino acid biosynthesis

\begin{tabular}{llll}
\hline SAOUHSC_00142 & $f d h$ & formate dehydrogenase & 4 \\
SAOUHSC_00421 & $m c c A$ & hypothetical protein & 5 \\
SAOUHSC_00898 & $\operatorname{argH}$ & argininosuccinate lyase & 8 \\
SAOUHSC_00899 & $\operatorname{argG}$ & argininosuccinate synthase & 13 \\
SAOUHSC_01319 & thrD & aspartate kinase & 3 \\
SAOUHSC_01321 & thrC & threonine synthase & 3 \\
SAOUHSC_01322 & thrB & homoserine kinase & 3 \\
SAOUHSC_01483 & aroC & chorismate synthase & 2 \\
SAOUHSC_02830 & ddh & D-lactate dehydrogenase & 2
\end{tabular}

Biosynthesis of cofactors, prosthetic groups, and carriers

\begin{tabular}{llll}
\hline SAOUHSC_00171 & $g g t$ & gamma-glutamyltranspeptidase & 3 \\
SAOUHSC_00386 & ss/3 & superantigen-like protein & 7 \\
SAOUHSC_00833 & & hypothetical protein & 4 \\
SAOUHSC_00877 & & hypothetical protein & 2
\end{tabular}




\begin{tabular}{|c|c|c|}
\hline SAOUHSC_01041 & $p d h B$ & $\begin{array}{l}\text { pyruvate dehydrogenase complex, E1 } \\
\text { component subunit beta }\end{array}$ \\
\hline SAOUHSC_01256 & & hypothetical protein \\
\hline SAOUHSC_01824 & thil & thiamine biosynthesis protein Thil \\
\hline SAOUHSC_02329 & thiM & hydroxyethylthiazole kinase \\
\hline SAOUHSC_02330 & thiD & phosphomethylpyrimidine kinase \\
\hline SAOUHSC_02536 & moaA & $\begin{array}{l}\text { molybdenum cofactor biosynthesis protein } \\
\text { A }\end{array}$ \\
\hline SAOUHSC_02537 & mobA & $\begin{array}{l}\text { molybdopterin-guanine dinucleotide } \\
\text { biosynthesis protein MobA }\end{array}$ \\
\hline C_02538 & moaD & molybdopterin converting factor subunit 1 \\
\hline SAOUHSC_02541 & mobB & $\begin{array}{l}\text { molybdopterin-guanine dinucleotide } \\
\text { biosynthesis protein MobB }\end{array}$ \\
\hline SAOUHSC_02543 & moaC & $\begin{array}{l}\text { molybdenum cofactor biosynthesis protein } \\
\text { MoaC }\end{array}$ \\
\hline SAOUHSC_OZ & & hypothetical protein \\
\hline
\end{tabular}

Cell envelope

\begin{tabular}{|c|c|c|}
\hline SAOUHSC_00157 & murQ & $\begin{array}{l}\mathrm{N} \text {-acetylmuramic acid-6-phosphate } \\
\text { etherase }\end{array}$ \\
\hline SAOUHSC_00295 & nanA & $\mathrm{N}$-acetylneuraminate lyase \\
\hline SAOUHSC_00426 & metQ2 & $A B C$ transporter substrate-binding protein \\
\hline SAOUHSC_00691 & uppP & $\begin{array}{l}\text { undecaprenyl pyrophosphate } \\
\text { phosphatase }\end{array}$ \\
\hline SAC & & hypothetical protein \\
\hline SAOL & murG & undecaprenyldiphospho- \\
\hline
\end{tabular}

SAOUHSC 01467

SAOUHSC 01739

SAOUHSC 01856

SAOUHSC_02107

SAOUHSC_02337

SAOUHSC_02802

Cellular processes

SAOUHSC 00364

SAOUHSC 00365

SAOUHSC 00773

SAOUHSC_01693

SAOUHSC_01739

SAOUHSC_01920

SAOUHSC_02426

SAOUHSC_02691

SAOUHSC_02692

SAOUHSC_02700 muramoylpentapeptide beta- $\mathrm{N}$ -

acetylglucosaminyltransferase

pbp2 penicillin-binding protein 2

lytH hypothetical protein

4

murT UDP-N-acetylmuramyl tripeptide 3

synthetase

murA1 UDP-N-acetylglucosamine 1-

carboxyvinyltransferase

$f n b B \quad$ fibronectin binding protein $B$

ahp $F \quad$ alkyl hydroperoxide reductase subunit $\mathrm{F} \quad 5$

ahpC alkyl hydroperoxide reductase subunit C 6

LysM domain-containing protein 4

comEA hypothetical protein 4

lytH hypothetical protein 2

hypothetical protein 4

hypothetical protein 3

hypothetical protein 4

hypothetical protein 5

$m d e A$ hypothetical protein 4 


\begin{tabular}{llll}
\hline SAOUHSC_00139 & & hypothetical protein & 4 \\
SAOUHSC_00295 & $\operatorname{nanA}$ & N-acetylneuraminate lyase & 2 \\
SAOUHSC_01504 & fer & ferredoxin & 3 \\
SAOUHSC_02564 & ureG & urease accessory protein UreG & 2
\end{tabular}

DNA metabolism

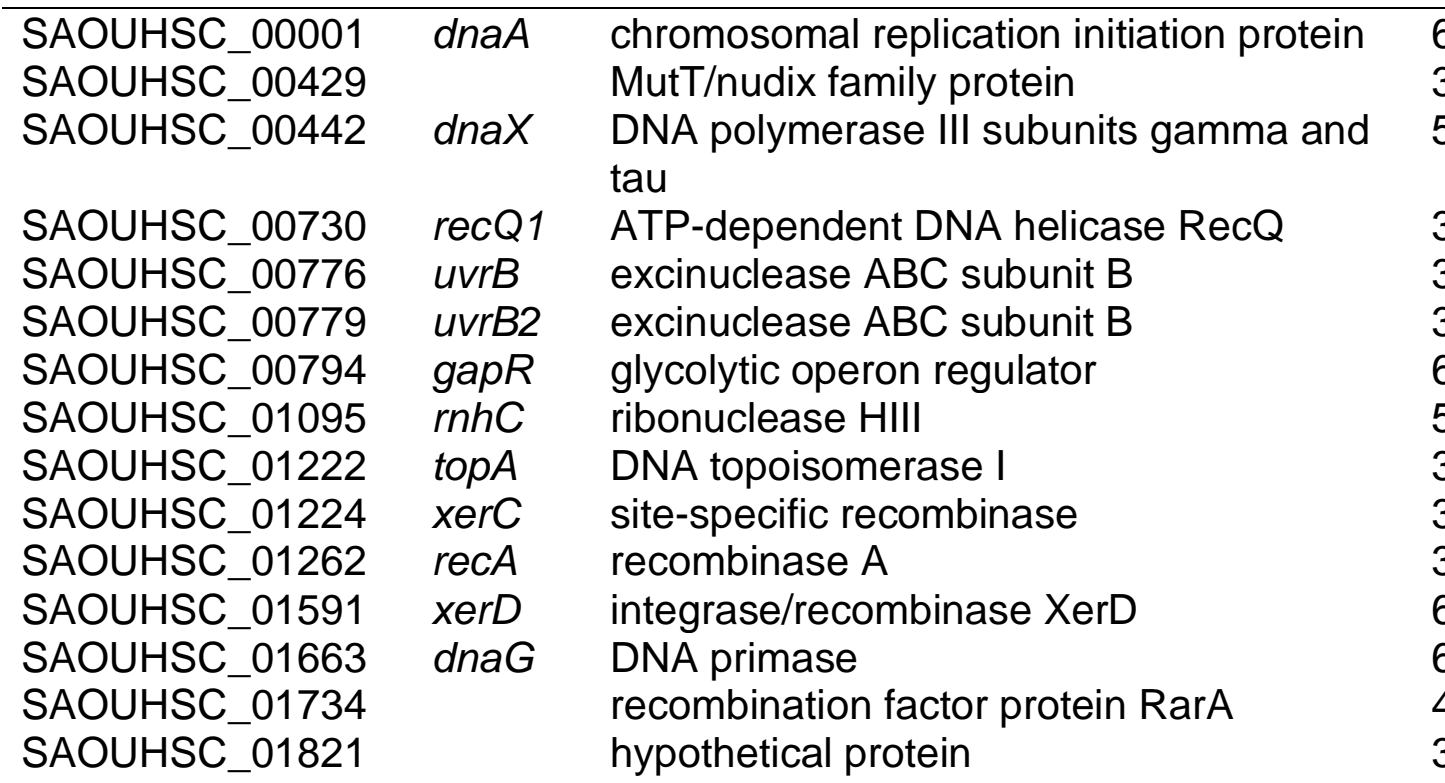

Energy metabolism

\begin{tabular}{|c|c|c|}
\hline SAOÜHSC_00219 & & hypothetical protein \\
\hline $\begin{array}{l}\text { SAOUHSC_00239 } \\
\text { SAOUHSC } 00291\end{array}$ & rbsK & $\begin{array}{l}\text { ribokinase } \\
\text { PfkR family }\end{array}$ \\
\hline SAOUHSC_00795 & gapA & $\begin{array}{l}\text { glyceraldehyde-3-phosphate } \\
\text { dehydrogenase }\end{array}$ \\
\hline SAOUHSC_01040 & $\operatorname{pdh} A$ & $\begin{array}{l}\text { pyruvate dehydrogenase complex, E1 } \\
\text { component subunit alpha }\end{array}$ \\
\hline SAOUHSC_01042 & $p d h C$ & $\begin{array}{l}\text { branched-chain alpha-keto acid } \\
\text { dehydrogenase subunit E2 }\end{array}$ \\
\hline SAOUHSC_01103 & $\operatorname{sdhC}$ & $\begin{array}{l}\text { succinate dehydrogenase cytochrome b- } \\
558 \text { subunit }\end{array}$ \\
\hline SAOUHSC_01278 & $g / p D$ & $\begin{array}{l}\text { aerobic glycerol-3-phosphate } \\
\text { dehydrogenase }\end{array}$ \\
\hline 01818 & ald2 & alanine dehydrogenase \\
\hline & rp/E & osomal protein L5 \\
\hline $0<90$ & $\operatorname{arcC}$ & carbamate kinase \\
\hline
\end{tabular}

Fatty acid and phospholipid metabolism

\begin{tabular}{|c|c|c|}
\hline SAOUHSC_00336 & & acetyl-CoA acyltransferase \\
\hline SAOUHSC_00661 & & hypothetical protein \\
\hline SAOUHSC_01197 & pls $X$ & glycerol-3-phosphate acyltransferase PIsX \\
\hline SAOUHSC_01198 & $f a b D$ & $\begin{array}{l}\text { malonyl CoA-acyl carrier protein } \\
\text { transacylase }\end{array}$ \\
\hline $\begin{array}{l}\text { SAOUHSC_01199 } \\
\text { SAOUHSC_01623 }\end{array}$ & $\begin{array}{l}f a b G \\
a c c C\end{array}$ & $\begin{array}{l}\text { 3-oxoacyl-(acyl-carrier-protein) reductase } \\
\text { acetyl-CoA carboxylase biotin carboxylase } \\
\text { subunit }\end{array}$ \\
\hline
\end{tabular}




\begin{tabular}{|c|c|c|}
\hline SAOUHSC_01624 & $a c c B$ & $\begin{array}{l}\text { acetyl-CoA carboxylase biotin carboxyl } \\
\text { carrier protein subunit }\end{array}$ \\
\hline SAOUHSC_01808 & $\operatorname{acc} A$ & $\begin{array}{l}\text { acetyl-CoA carboxylase } \\
\text { carboxyltransferase subunit alpha }\end{array}$ \\
\hline SAOUHSC_01809 & $a c c D$ & $\begin{array}{l}\text { acetyl-CoA carboxylase } \\
\text { carboxyltransferase subunit beta }\end{array}$ \\
\hline SAOUHSC_02336 & $f a b Z$ & (3R)-hydroxymyristoyl-ACP dehydratase \\
\hline
\end{tabular}

Mobile and extrachromosomal element functions

\begin{tabular}{lll}
\hline SAOUHSC_02180 & phage minor structural protein & 3 \\
SAOUHSC_02185 & phi PVL orf 13-like protein & 5 \\
SAOUHSC_02187 & HK97 family phage protein & 12 \\
SAOUHSC_02691 & hypothetical protein & 4 \\
SAOUHSC_02692 & hypothetical protein & 5
\end{tabular}

Protein fate

\begin{tabular}{|c|c|c|}
\hline SAOUHSC_00531 & & hypothetical protein \\
\hline SAOUHSC_00902 & sps $A$ & signal peptidase IA \\
\hline SAOUHSC_01225 & $c / p Q$ & $\begin{array}{l}\text { ATP-dependent protease peptidase } \\
\text { subunit }\end{array}$ \\
\hline SAOUHSC_01226 & $h s / U$ & $\begin{array}{l}\text { ATP-dependent protease ATP-binding } \\
\text { subunit HsIU }\end{array}$ \\
\hline SAOU & & hypothetical protein \\
\hline SAOU & $\sec D F$ & $\begin{array}{l}\text { bifunctional preprotein translocase subunit } \\
\text { SecD/SecF }\end{array}$ \\
\hline & groE & chaperonin GroEL \\
\hline & yidC & hypothetical protein \\
\hline JHSC_O & & hypothetical protein \\
\hline OUHSC_02941 & $n r d G$ & hypothetical protein \\
\hline
\end{tabular}

Protein synthesis

SAOUHSC 00035

$\operatorname{cst} A \quad$ hypothetical protein 4

SAOUHSC_00348

rpsF 30 S ribosomal protein S6

5

2

2

2

SAOUHSC_00350

rpsR

SAOUHSC_00430

SAOUHSC 00484

SAOUHSC 00518

SAOUHSC 00519

SAOUHSC_01211

SAOUHSC_01425

SAOUHSC 01741

SAOUHSC_01748

SAOUHSC_01755

SAOUHSC_01757

SAOUHSC_01784

SAOUHSC_01785

SAOUHSC_01786

SAOUHSC 01824

SAOUHSC_01829

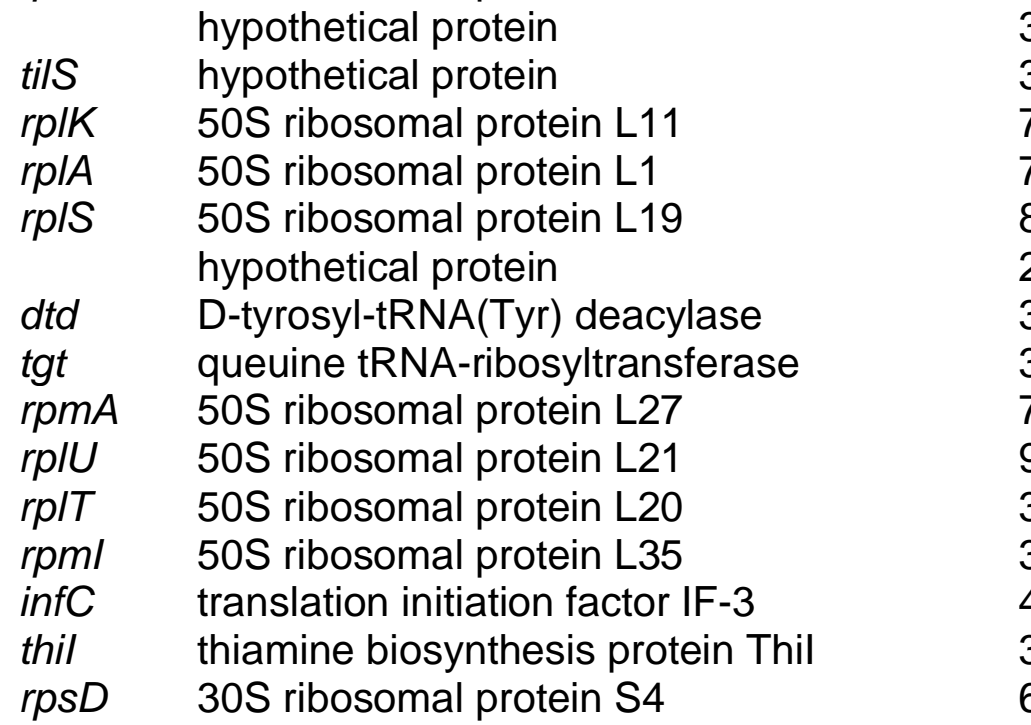




\begin{tabular}{|c|c|c|}
\hline SAOUHSC_02116 & gatB & $\begin{array}{l}\text { aspartyl/glutamyl-tRNA amidotransferase } \\
\text { subunit B }\end{array}$ \\
\hline SAOUHSC_02117 & gat $A$ & $\begin{array}{l}\text { aspartyl/glutamyl-tRNA amidotransferase } \\
\text { subunit } A\end{array}$ \\
\hline SAOUHSC_02370 & & hypothetical protein \\
\hline SAOUHSC_02501 & $r p / X$ & 50 S ribosomal protein L24 \\
\hline SAOUHSC_02503 & rpsQ & $30 S$ ribosomal protein $\mathrm{S} 17$ \\
\hline SAOUHSC_02504 & rpmC & 50 S ribosomal protein L29 \\
\hline SAOUHSC_02505 & rplP & $50 S$ ribosomal protein L16 \\
\hline SAOUHSC_02506 & rpsC & 30S ribosomal protein S3 \\
\hline SAOUHSC_02507 & rp/V & $50 S$ ribosomal protein L22 \\
\hline SAOUHSC_02508 & rpsS & $30 S$ ribosomal protein $\mathrm{S} 19$ \\
\hline SAOUHSC_02509 & rp/B & $50 S$ ribosomal protein L2 \\
\hline SAOUHSC_02510 & rp/W & 50 S ribosomal protein L23 \\
\hline SAOUHSC_02511 & $r p / D$ & $50 S$ ribosomal protein L4 \\
\hline SAOUHSC_02827 & & hypothetical protein \\
\hline SAOUHSC_03053 & trmE & tRNA modification GTPase TrmE \\
\hline SAOUHSC_03055 & rpmH & 50 S ribosomal protein L34 \\
\hline
\end{tabular}

Purines, pyrimidines, nucleosides, and nucleotides

\begin{tabular}{|c|c|c|}
\hline SAOUHSC_00019 & purA & adenylosuccinate synthetase \\
\hline SAOUHSC_01171 & pyrF & orotidine 5'-phosphate decarboxylase \\
\hline SAOUHSC_01172 & pyrE & orotate phosphoribosyltransferase \\
\hline SAOUHSC_01330 & guaC & $\begin{array}{l}\text { guanosine } 5^{\prime} \text {-monophosphate } \\
\text { oxidoreductase }\end{array}$ \\
\hline SAOUHSC_02941 & $n r d G$ & hypothetical protein \\
\hline SAOUHSC_02942 & $n r d D$ & $\begin{array}{l}\text { anaerobic ribonucleoside triphosphate } \\
\text { reductase }\end{array}$ \\
\hline
\end{tabular}

Regulatory functions

$\begin{array}{llll}\text { SAOUHSC_00096 } & & \text { GntR family transcriptional regulator } & 2 \\ \text { SAOUHSC_01228 } & \text { codY } & \text { transcriptional repressor CodY } & 4 \\ \text { SAOUHSC_01320 } & \text { hom } & \text { homoserine dehydrogenase } & 5 \\ \text { SAOUHSC_01850 } & \text { ccpA } & \text { catabolite control protein A } & 3 \\ \text { SAOUHSC_02799 } & \text { sarT } & \text { accessory regulator T } & 8 \\ \text { SAOUHSC_03027 } & & \text { hypothetical protein } & 4 \\ \text { SAOUHSC_03046 } & & \text { helix-turn-helix domain-containing protein } & 5\end{array}$

Signal transduction

SAOUHSC 00213

hypothetical protein

4

Transcription

\begin{tabular}{llll}
\hline SAOUHSC_00524 & $r p o B$ & $\begin{array}{l}\text { DNA-directed RNA polymerase subunit } \\
\text { beta }\end{array}$ & 3 \\
SAOUHSC_01662 & sigA & $\begin{array}{l}\text { RNA polymerase sigma factor RpoD } \\
\text { ribonuclease P }\end{array}$ & 3 \\
SAOUHSC_03054 & rnpA & ribule & 13
\end{tabular}

Transport and binding proteins

SAOUHSC_00105 phnD $\begin{aligned} & \text { phosphonate ABC transporter substrate- } 11 \\ & \text { binding protein }\end{aligned}$


SAOUHSC 00136

SAOUHSC_00137

SAOUHSC_00138

SAOUHSC_00167

SAOUHSC_00168

SAOUHSC_00169

SAOUHSC_00241

SAOUHSC_00282

SAOUHSC_00315

SAOUHSC_00317

SAOUHSC 00880

SAOUHSC_00928

SAOUHSC_01340

SAOUHSC_01346

SAOUHSC_01656

SAOUHSC 01657

SAOUHSC_02108

SAOUHSC 02321

SAOUHSC_02622

SAOUHSC 02660

SAOUHSC 02700

SAOUHSC_02704

SAOUHSC_02750

SAOUHSC_02864

SAOUHSC_02866

SAOUHSC_02874

SAOUHSC_02937
ssuB

ssuA

ssuC

rbsU

brnQ2

mepA

glp $T$

opp-4A

hypothetical protein

10

hypothetical protein

10

hypothetical protein

peptide $A B C$ transporter ATP-binding

protein

hypothetical protein

peptide $A B C$ transporter permease

hypothetical protein

branched-chain amino acid transport

system II carrier protein

hypothetical protein

glycerol-3-phosphate transporter

hypothetical protein

6

4

17

12

6

5

17

6

53

oligopeptide ABC transporter substrate- 12

binding protein

hypothetical protein

opuD1 glycine betaine transporter 12

znuB hypothetical protein 3

znuC ABC transporter 3

$\begin{array}{lll}\text { ftnA ferritin } & 12\end{array}$

hypothetical protein 10

gltS sodium/glutamate symporter 3

cobl hypothetical protein 3

$m d e A$ hypothetical protein 4

hypothetical protein 2

hypothetical protein 5

$\begin{array}{lll}f e o B & \text { ferrous iron transport protein } B & 11\end{array}$

hypothetical protein 3

copZ cation transporter E1-E2 family ATPase 3

cudT choline transporter 3

Unknown TIGRFAM main role

$\begin{array}{llll}\text { SAOUHSC_00135 } & & \begin{array}{l}\text { hypothetical protein } \\ \text { hypothetical protein }\end{array} & 4 \\ \text { SAOUHSC_00141 } & & \begin{array}{l}\text { RGD-containing lipoprotein } \\ \text { SAOUHSC_00170 }\end{array} & 2 \\ \text { SAOUHSC_00173 } & \text { azoR } & \text { azoreductase } & 7 \\ \text { SAOUHSC_00240 } & \text { rbsD } & \text { D-ribose pyranase } & 4 \\ \text { SAOUHSC_00268 } & \text { esaD } & \text { hypothetical protein } & 3 \\ \text { SAOUHSC_00269 } & \text { esaG } & \text { hypothetical protein } & 5 \\ \text { SAOUHSC_00270 } & & \text { hypothetical protein } & 3 \\ \text { SAOUHSC_00290 } & & \text { hypothetical protein } & 2 \\ \text { SAOUHSC_00296 } & \text { nanK } & \text { ROK family protein } & 2 \\ \text { SAOUHSC_00300 } & \text { geh } & \text { lipase } & 5 \\ \text { SAOUHSC_00301 } & & \text { hypothetical protein } & 3 \\ \text { SAOUHSC_00302 } & & \text { hypothetical protein } & 4 \\ \text { SAOUHSC_00309 } & & \text { hypothetical protein } & 17 \\ \text { SAOUHSC_00314 } & \text { mepR } & \text { hypothetical protein } & 3 \\ \text { SAOUHSC_00316 } & \text { mepB } & \text { hypothetical protein } & 3 \\ \text { SAOUHSC_00334 } & & \text { hypothetical protein } & 2 \\ \text { SAOUHSC_00367 } & \text { tcyP } & \text { hypothetical protein } & 3\end{array}$




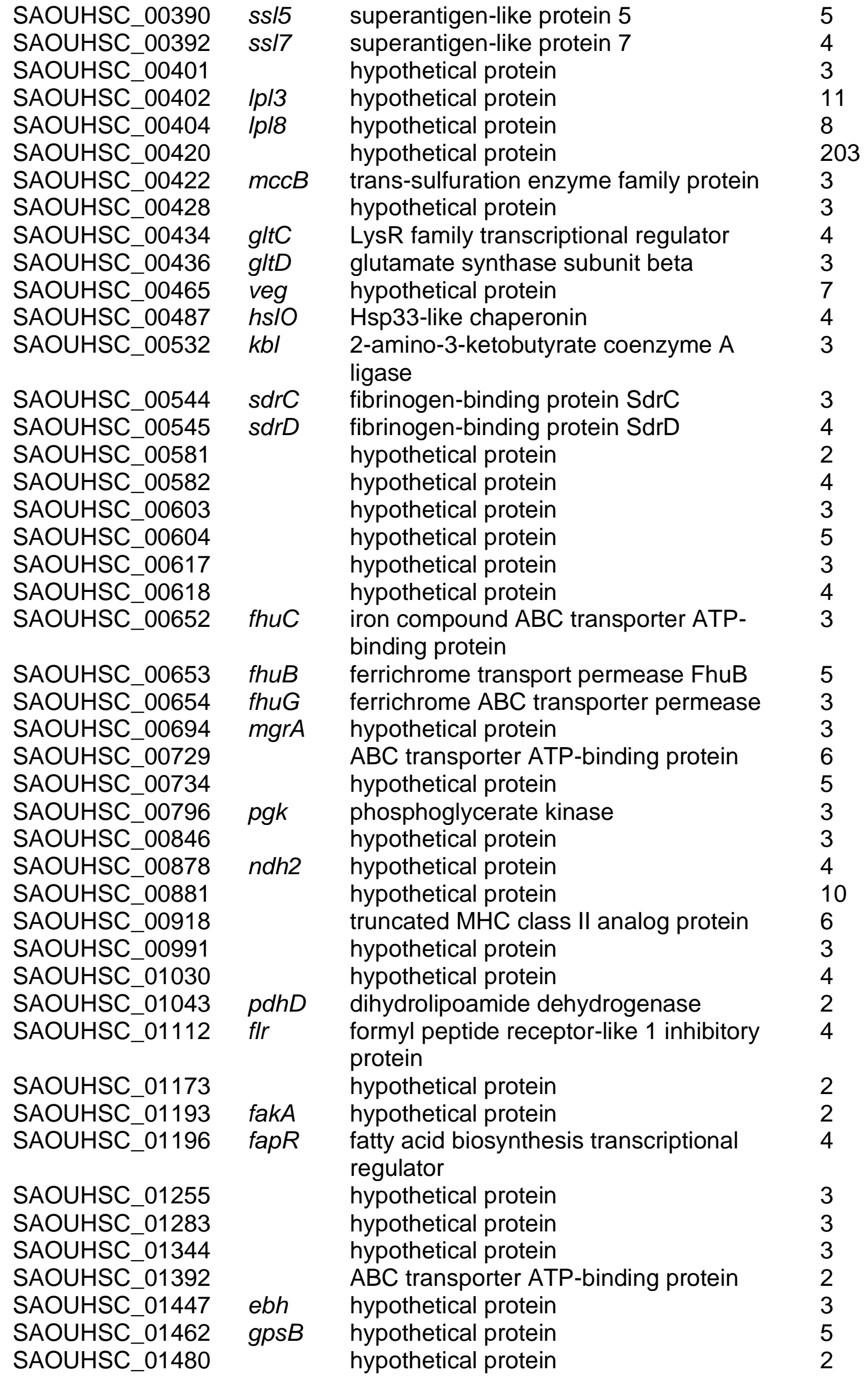


SAOUHSC_01499

SAOUHSC_01520

SAOUHSC 01521

SAOUHSC 01590

SAOUHSC_01592

SAOUHSC_01603

SAOUHSC_01604

SAOUHSC_01723

SAOUHSC_01724

SAOUHSC 01732

SAOUHSC 01733

SAOUHSC_01756

SAOUHSC_01762

SAOUHSC_01843

SAOUHSC_01873

SAOUHSC_02073

SAOUHSC_02080

SAOUHSC_02167

SAOUHSC_02171

SAOUHSC 02184

SAOUHSC 02255

SAOUHSC_02272

SAOUHSC 02322

SAOUHSC 02331

SAOUHSC 02333

SAOUHSC_02404

SAOUHSC 02406

SAOUHSC_02407

SAOUHSC_02436

SAOUHSC_02460

SAOUHSC 02462

SAOUHSC 02463

SAOUHSC 02498

SAOUHSC 02512

SAOUHSC 02540

SAOUHSC_02571

SAOUHSC 02587

SAOUHSC_02628

SAOUHSC_02659

SAOUHSC 02703

SAOUHSC 02737

SAOUHSC_02798

SAOUHSC 02825

SAOUHSC 02826

SAOUHSC_02828

SAOUHSC 02873

SAOUHSC_02883

SAOUHSC_02892

SAOUHSC_02893 hypothetical protein

SLT orf 488-like protein

SLT orf 636-like protein

hypothetical protein

fur

transcriptional regulator Fur

hypothetical protein

hypothetical protein

hypothetical protein

hypothetical protein

cymR

hypothetical protein

hypothetical protein

hypothetical protein

hypothetical protein

isd $H \quad$ hypothetical protein $\quad 17$

sasC hypothetical protein 5

hypothetical protein 4

bacteriophage L54a antirepressor 3

$\begin{array}{lll}\text { scn } & \text { hypothetical protein } & 2 \\ \text { sak } & \text { staphylokinase } & 3\end{array}$

phi PVL orf 14-like protein 22

groES co-chaperonin GroES 3

hypothetical protein 3

hypothetical protein 12

$\operatorname{ten} A$ hypothetical protein 5

sceD transglycosylase SceD 3

$f m t B$ hypothetical protein 3

hypothetical protein 3

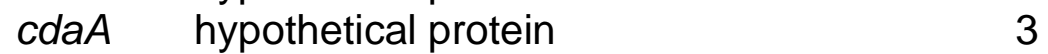

hypothetical protein 3

hypothetical protein 2

hypothetical protein 9

hys $A$ hyaluronate lyase 5

$\mathrm{rpsH} 30 \mathrm{~S}$ ribosomal protein S8 3

rp/C $50 \mathrm{~S}$ ribosomal protein $\mathrm{L} 3 \quad 5$

moaE molybdopterin converting factor moa 5

$\begin{array}{lll}\text { ssaA secretory antigen } & 10\end{array}$

$s p d B \quad$ hypothetical protein $\quad 4$

hypothetical protein 2

hypothetical protein 3

gpmA 2,3-bisphosphoglycerate-dependent 6 phosphoglycerate mutase epimerase/dehydratase 9

sas $G \quad$ hypothetical protein 3

hypothetical protein 10

hypothetical protein 5

hypothetical protein 6

copA cation transporter E1-E2 family ATPase 4

LysM domain-containing protein 3

hypothetical protein 5

hypothetical protein 5 
SAOUHSC_02894

SAOUHSC_02963

SAOUHSC_03022

SAOUHSC_03049

SAOUHSC_A00332

SAOUHSC_A01912

SAOUHSC_T00026

SAOUHSC_T00030 hypothetical protein

5

clfB

clumping factor $B$

hypothetical protein

hypothetical protein

hypothetical protein

hypothetical protein

tRNA-His

trnaH

trnaL 